\title{
The Spatial Planning for the Educational Services and the Scarcity of Urban Land: Study Area: Al-Sadder City
}

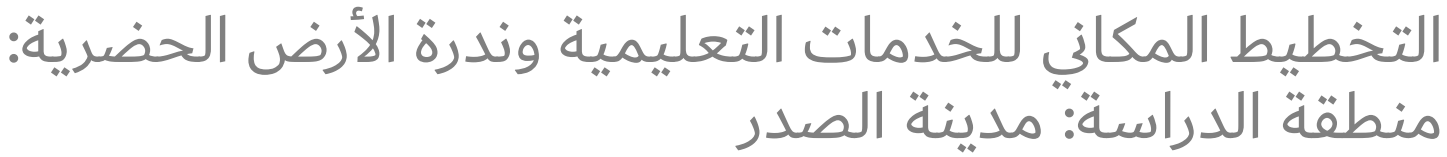

Moheeb Kamil Flayeh and Adil Kareem Hamil

مهيب كامل الراوي وعادل كريم هامل

Center of Urban And Regional Planning For Post Graduate Studies, Baghdad - Iraq

مركز التخطيط الحضري والإقليمي للدراسات العليا، بغداد - العراق

\section{Abstract}

Many Of Cities Are experiencing a real shortage and need for school buildings due

Corresponding Author: Moheeb Kamil Flayeh mohalrawi_74@yahoo.com Received: 28 December 2017 Accepted: 2 February 2018 Published: 1 May 2018

Publishing services provided by Knowledge

(c) Moheeb Kamil Flayeh and Adil Kareem Hamil. This article is distributed under the terms of the Creative Commons

Attribution License, which permits unrestricted use and redistribution provided that the original author and source are credited.

Selection and Peer-review under the responsibility of the Urban Planning Iraq Conference Committee. to overcrowding and duplication in school attendance, The growth of educational institutions has been barge into the scarcity of urban land required for the construction of school buildings. In order to address this scarcity, the cities needs to adopt one or more urban policies to address the scarcity of allocated land For educational services.

تشهد مناطق عديدة عجز وحاجة فعلية للأبنية المدرسية بسبب الاكتظاظ والازدواج في الدوام المدرسي،

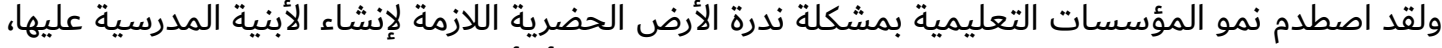
ولهذا تحتاج المدن لمعالجة هذه الندرة إلى اعتماد سياسة حضرية أو أكثر للعمل على معالجة ندرة الأراضي المخصصة للخدمات التعليمية.

Keywords: Educational Services, Planning Standards, Urban Land Policies, Urban Land Scarcity.

الكلمات المفتاحية: الخدمات التعليمية، المعايير التخطيطية، سياسات الأرض الحضرية، ندرة الأرض الحضرية. مششكلة البحث وجود قصور في معالجة ندرة الأراضي المخصصة للخدمات التعليمية في مدينة الصدر.

\section{G OPEN ACCESS}


إن اعتماد سياسة (نقل بعض استعمالات الأرض خارج المدينة) على المدى القريب وسياسة (بيئة التعليم الافتراضية) على المدى البعيد سيساهم في تجاوز مشكلة ندرة الأراضي المخصصة للخدماتي المدات التعليمية في

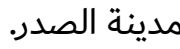

هدف البحث

تجاوز مشكلة ندرة الأراضي اللازمة للخدمات التعليمية على المدى القريب والبعيد.

\section{ا. الخدمات التعليمية ومعاييرها التخطيطية}

\section{| - إ. الخدمات المجتمعية}

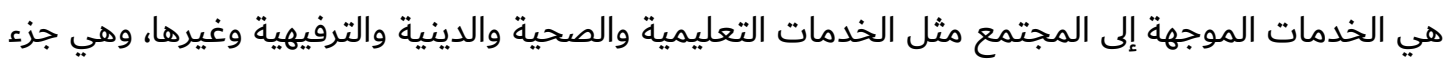

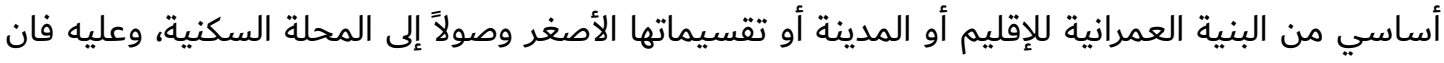

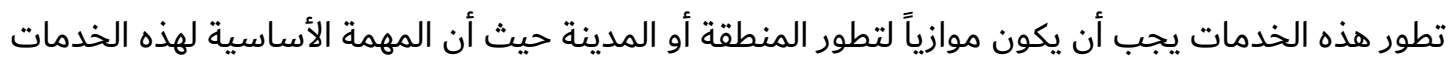
هو تلبية احتياجات السكان بالمستوى والكم المطلوبين (1).

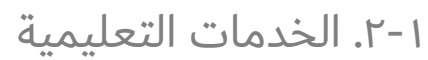

إن الخدمات التعليمية من أهم الخدمات المجتمعية، إذ يقاس مستوى المجتمع بالمستوى العلمي لأبنائه،

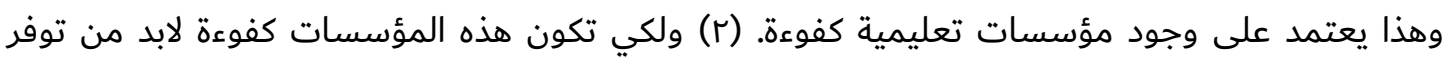

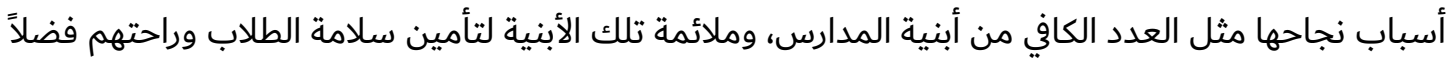

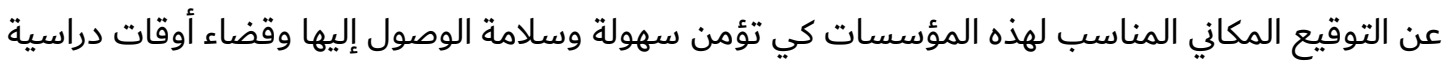

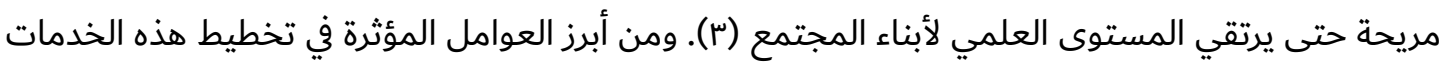

ا. الزيادة السكانية، حيث ينعدم توازن عدد السكان مع الخدمات.

r. الإدارة، حيث تلعب الإدارة دوراً مهماً في تنظيم حياة المجتمع.

". التخصيص المالي، إذ تحتاج هذه الخدمات لأموال كبيرة نسبياً.

ع. الخبرة التخطيطية، وتكمن في توفير خدمات تعليمية تلبي حاجة السكان بأقل جهد وزمن وتكلفة.

|-r-1 إ مستويات تخطيط الخدمات التعليمية

تتوزع الخدمات التعليمية على المستويات التخطيطية للمدينة كما في الشكل التالي: 


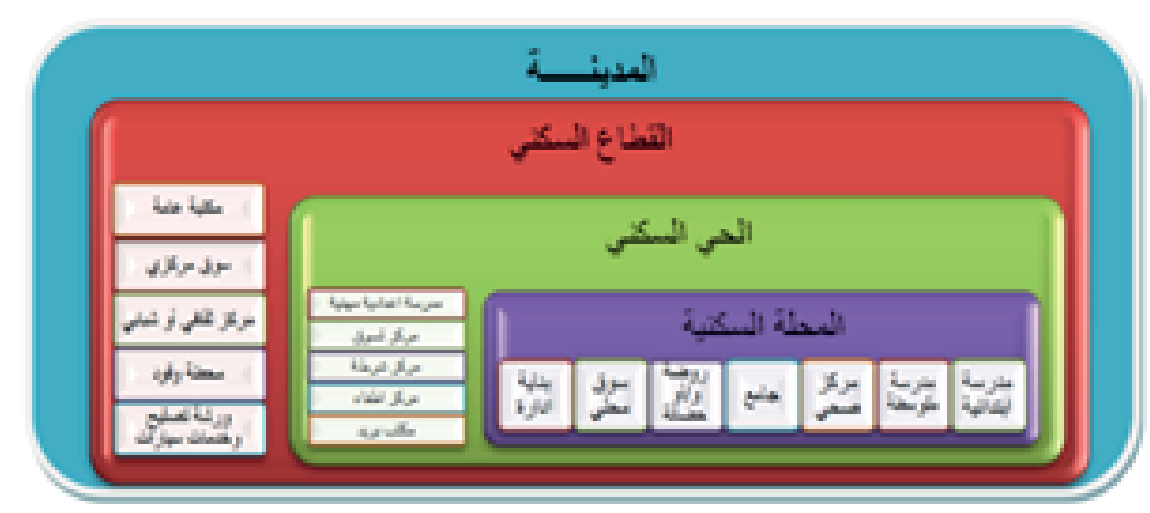

شكل ا: توزيع الخدمات التعليمية على المستويات التخطيطية للمدينة (0).

I-r-r-r. معايير التخطيط المكاني للخدمات التعليمية

توجد العديد من المعايير أهمها (7) :

ا. تحقيق سهولة الوصول بين السكن والمدارس وتأمين عدم عبور الأطفال للشوارع إن أمكن. r. تحديد مستويات ونوعية المؤسسات التعليمية عند الشروع بالتخطيط لتلك المؤسسات لكي يتم تخصيص النطاق المكاني لها وذلك حسب وناجة السؤسات التعان.

ب. تحديد موقع المدرسة بالنسبة للمنازل والمباني العامة كالصحية والمراكز الرياضية والاجتماعية. ع. مراعاة اختيار الموقع للمباني التعليمية في منطقة هادئة بعيداً عن الضجيج قدر الإمكان. 0. توفير مساحات كافية للملاعب الرياضية.

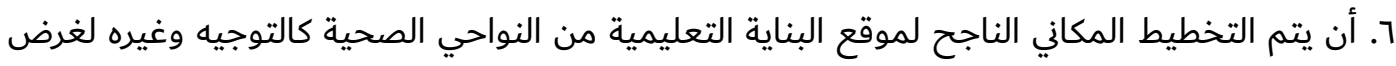

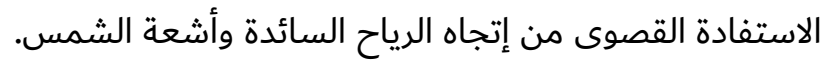
v. أن يكون موقع أبواب المدارس الخارجية من جهة الشوارع الفرعية لتلافي وقوع الحوادث للطلاب. ^. أن يتم تحديد المواقع للأبنية التعليمية بمحاذاة المناطق الخضراء لتوفير إطلالة جميلة وأجواء مريحة في البيئة التعليمية، فضلاً عن حجب منطقة السكن عن منطقة المدارس وبالتالي تحقيق العزل البصري والصوتي لكل من المنطقتين.

\section{r. ندرة الأرض الحضرية}

\section{r-1. تعريف مفهوم ندرة الأرض الحضرية}

إن مفهوم ندرة الأرض الحضرية يمثل مفهوما عالميا حيث تعرف الأرض الحضرية بأنها سلعة نادرة في البيئة

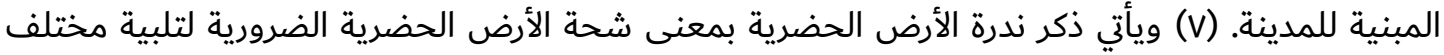

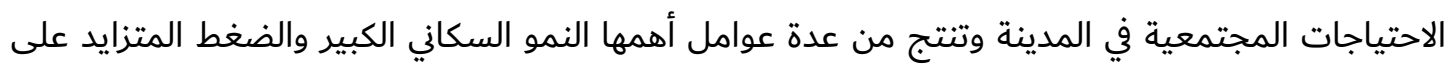

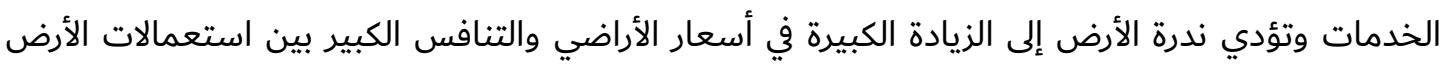


المختلفة على الأراضي المتوفرة ضمن المدينة، كما يؤدي ذلك أحيانا إلى الاتجاه للأراضي الزراعية المتاخمة للمدينة لاستغلالها لتوفير المنشآت التي تقدم مختلف الخدمات لسكان المدينة (^). وتعتبر الأرض المفتاح لفهم جانبين مهمين للتنمية الحضرية : ا. أنها مهمة جداً في تفسير الشكل والتصميم والنمو الحضري. r. أنها مركز الأنشطة في المدينة، وتؤثر على التنمية الاقتصادية التي تمنح القوة وتحديد العلاقات بين الجماعات الاجتماعية المختلفة والأنشطة. (9) الأشطة علي المدينة ومن غير المعلوم مقدار مساحة الأرض التي تغطيها المدن العالمية معاً، حيث هناك اختلاف كبير في

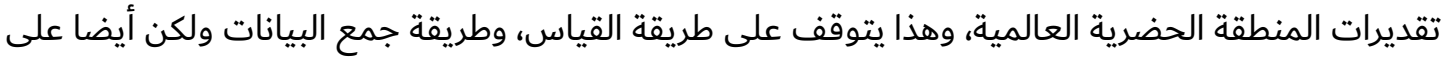

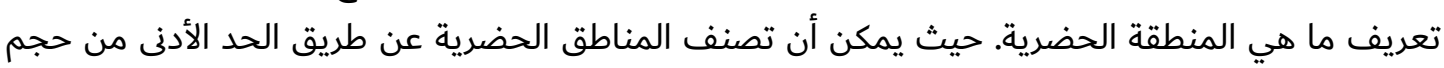

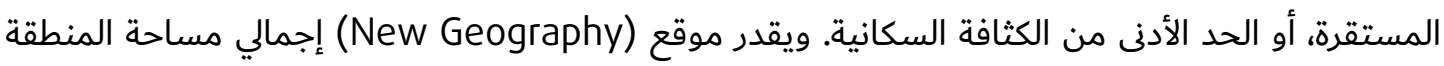

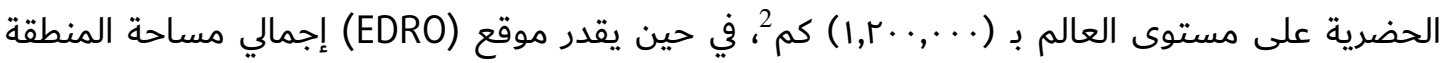

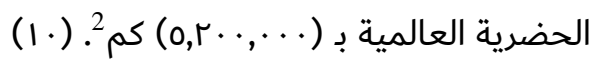
r-r. أهمية الأرض الحضرية تتمثل أهمية الأرض الحضرية بالجوانب الثلاث الآتية : r-r-1 أهمية الأرض الحضرية كمورفولوجيا

تمتلك كل مدينة مورفولوجيا وأنماط استعمال أراضي مختلفة تتراوح بين الانتظام والعشوائية سواء كان

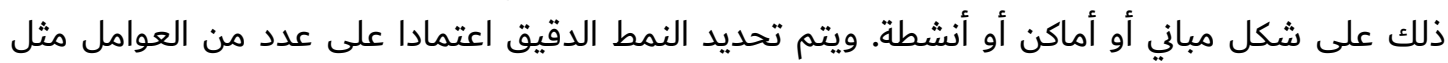

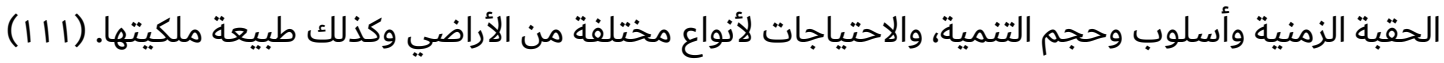

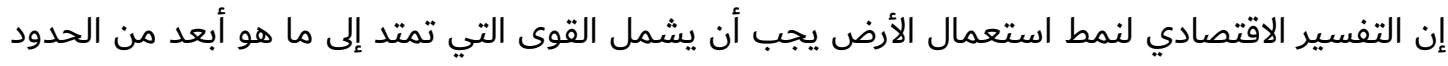

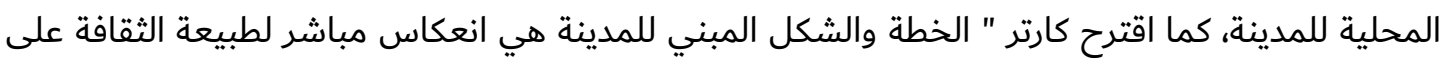

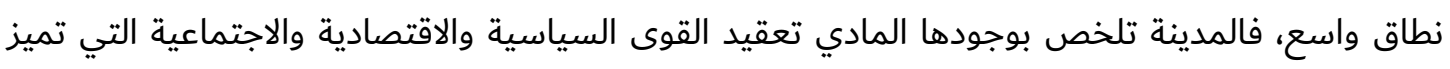

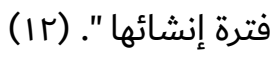

\section{r-r-r-r. أهمية الأرض كقوة وسلطة}

إن ملكية الأراضي تمنح القوة الاقتصادية والسياسية الكبيرة، وقد شهد القرن العشرين ظهور ونمو مطرد

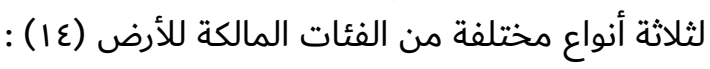

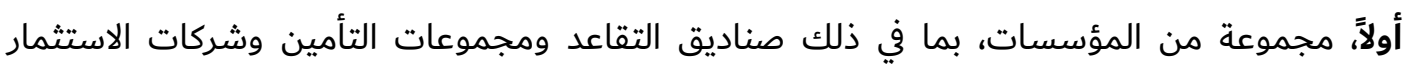

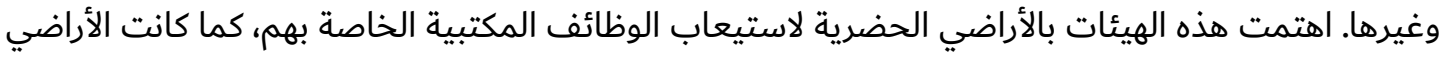

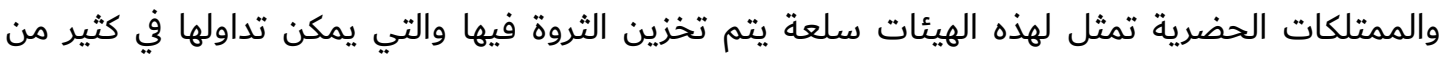

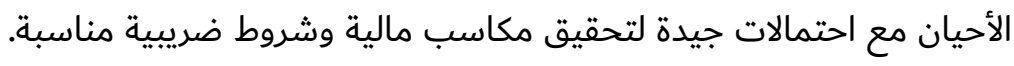


ثانياً، مالكي الأرض في المناطق الحضرية من القطاع العام، وهذا يشمل الحكومة المركزية والمحلية والمرافق العامة والصناعات المملوكة للدولة وعدد من الهيئات الحكومية وشبه الحكومية الأخرى.

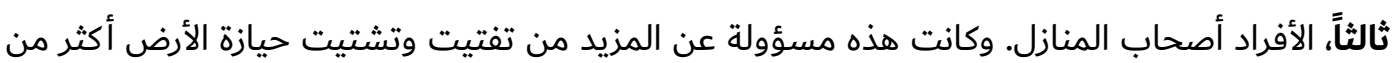

\section{r-r-r أهمية الأرض كأساس لنظام التخطيط}

تشكل الأرض جزء كبير من أساس تخطيط المدن، فقد كانت مهنة التخطيط التي بدأت في الظهور مع بداية

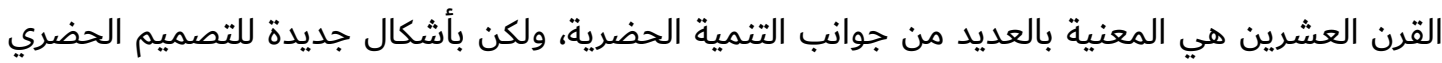

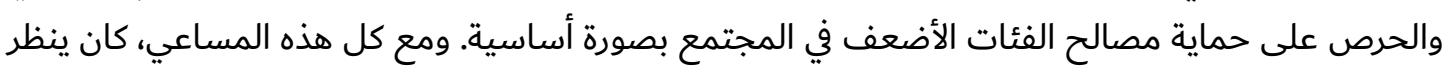
إلى المهمة المركزية أنها التغلب على أسوء جوانب الخليط المزدحمة وغير الصحية لاستعمالات الأراضي التي التي كاني

اتسمت به المدينة الصناعية. (10)

\section{r-س. التحضر وندرة الأرض الحضرية}

إن التحضر في المناطق يزيد من ندرة الأراضي، فهو يحول الأراضي الزراعية إلى مناطق حضرية. وبالتالي من

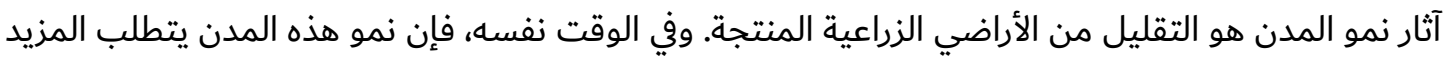

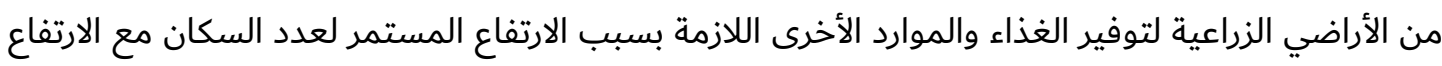

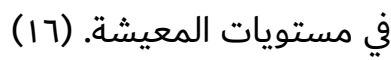

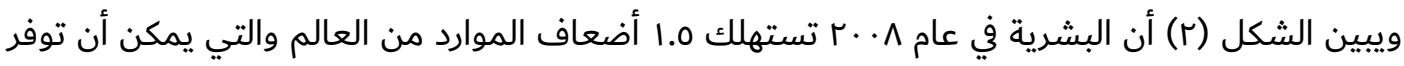

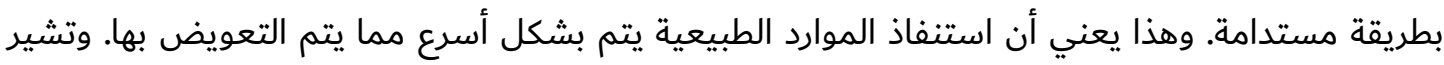

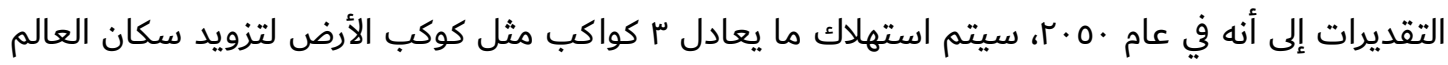

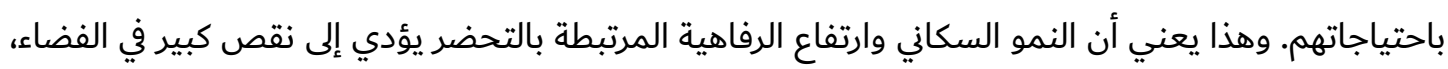

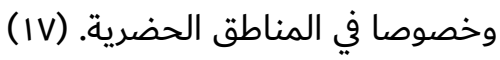

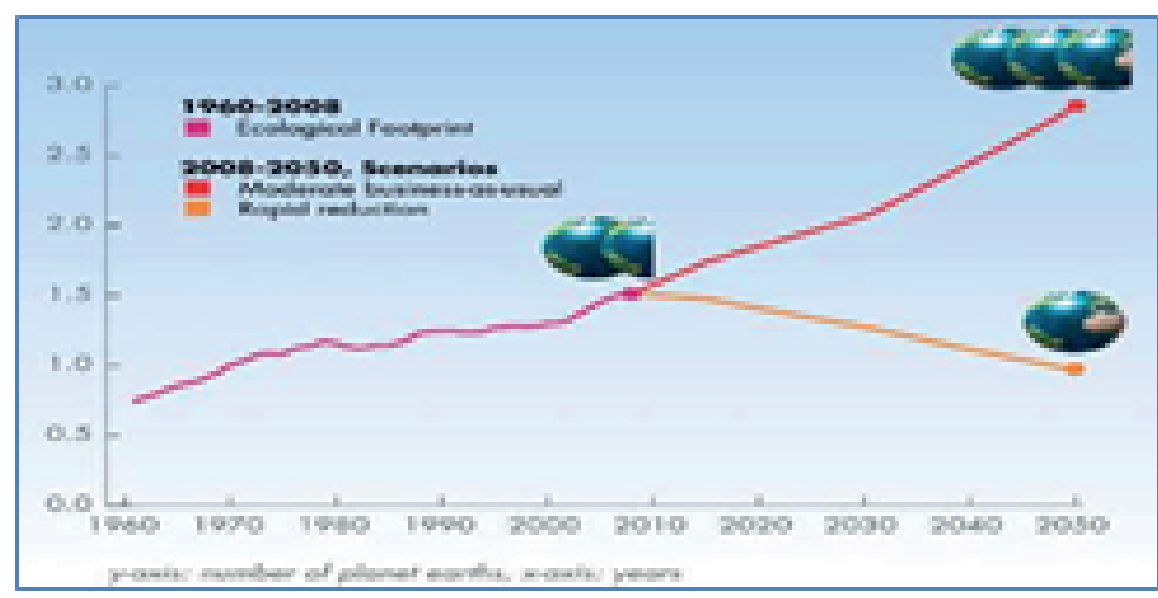

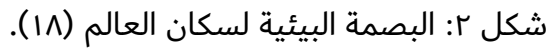




\section{r-ع. سياسات معالجة ندرة الأراضي الحضرية}

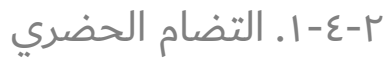

المدينة المتضامة تعرف بأنها مدينة المسافات القصيرة التي تسهم في ترشيد استهلاك الأراضي، وتعزز

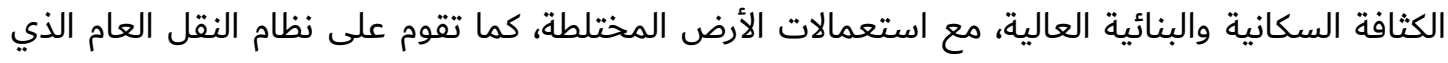

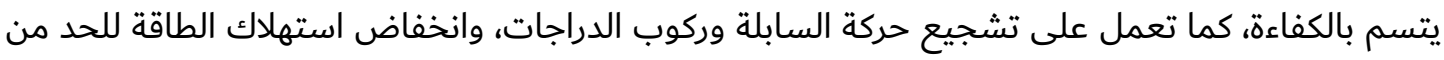

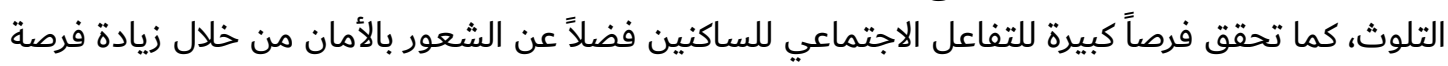

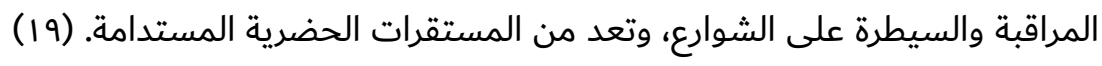

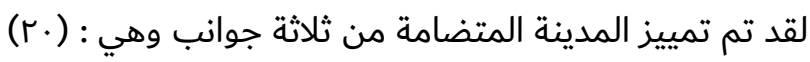
ا. شكل الفضاء، ويشمل المستوطنات ذات كثافة عالية، وقلة الاعتماد على السيارات، والحدود الواضحة مع المنطقة المحيطة. r. خصائص الفضاء، تتضمن هذه الخصائص تعدد الاستعمالات، وتنوع الحياة، والهوية الواضحة. ب.. الوظيفة، مثل العدالة الاجتماعية، والاكتفاء الذاتي للحياة اليومية، والاستقلالية في الحكم.

وهو مجموعة من مبادئ التخطيط الحضري والإقليمي المتماسكة التي تعمل على تحقيق أفضل نمط

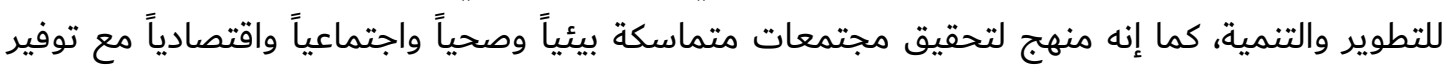

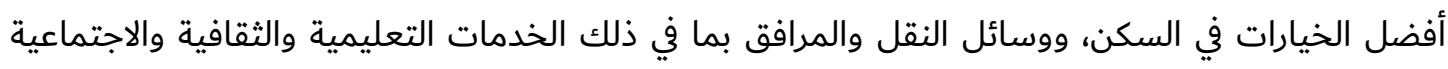

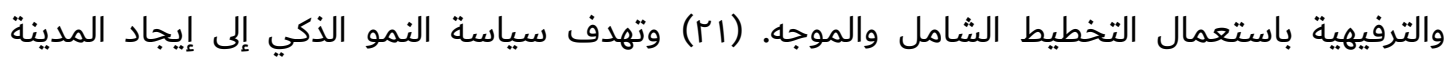

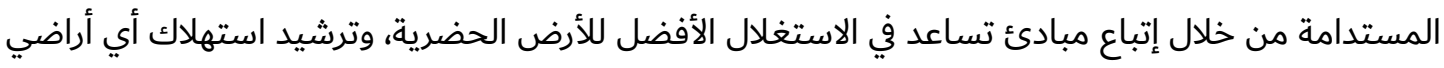
إضافية لاستيعاب النمو السكاني مع الحؤول دون تضخم المدينة وتعديها على ما يجاورها من أراضي زبادئ زاعية.

\section{r-ع-r. التكثيف الحضري}

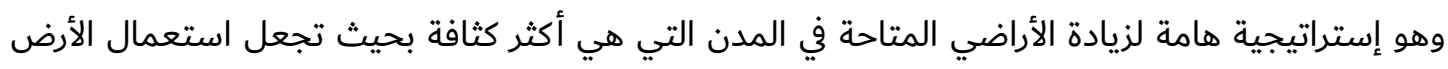

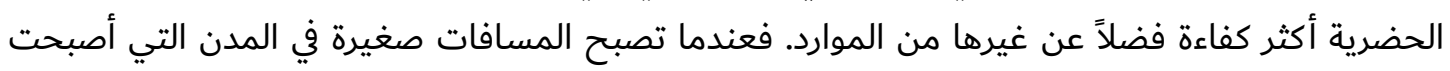

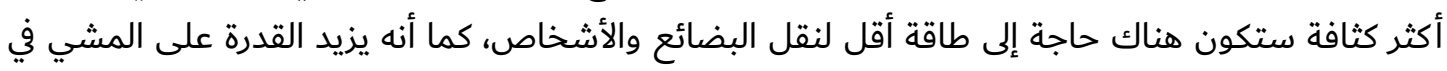

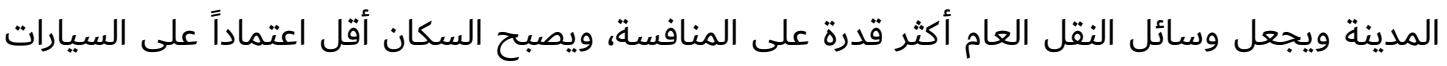

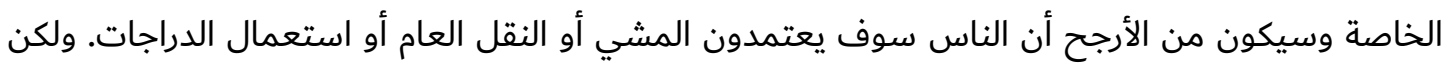

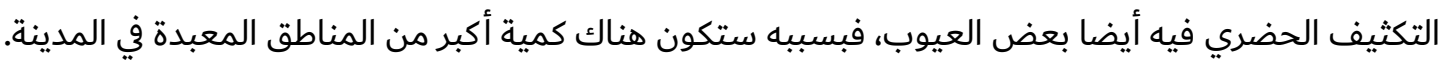
والنتيجة هي حصول عملية الجريان السطحي بشكل أسرع عند سقوط الأمطار والتي سوف تؤدي أحياناً إلى

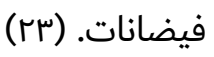


الفضاء متعدد الوظائف هو استخدام الحيز الحضري لأكثر من وظيفة واحدة لزيادة كفاءة استخدام الأراضي.

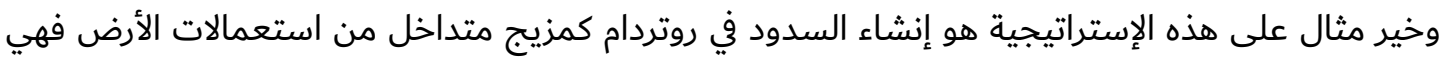

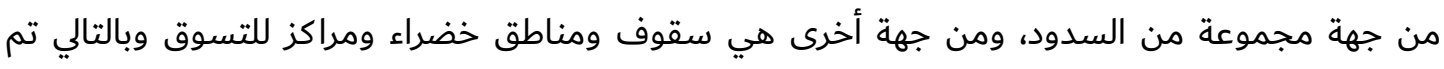
اجتياز عقبة ندرة الأرض اللازمة لتلك الفعاليات كما لم يتم تجاهل ضرورة إنشاء السدود لحمد لحماية المدينة

الشكل (r). (ع (r)

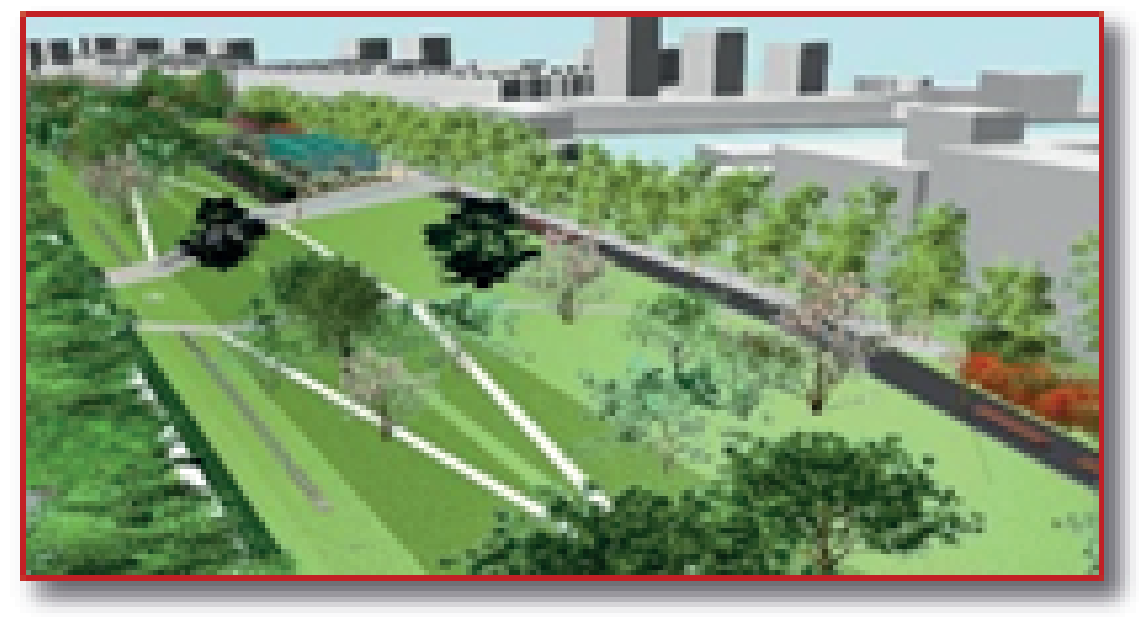

شكل rّ: حديقة السقف التي تتكامل مع السدود روتردام (ro) )

ومن ابرز أمثلتها المدن العائمة (Floating Cities) والتي قد تكون حلولاً تخطيطية لنمو المدن الساحلية

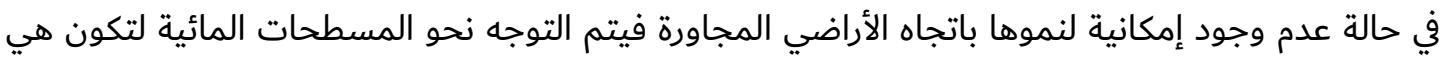

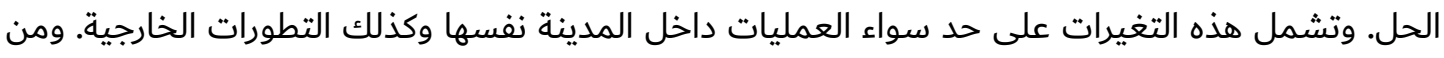

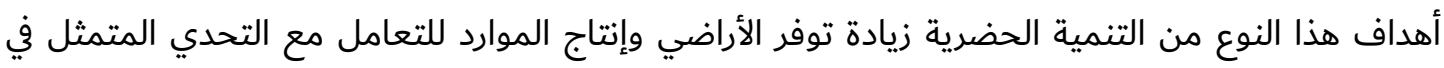
ندرة الطاقة والحد من الآثار السلبية للمدن على البيئة والتحرك نحو تدوير تدفقات الموارد (ج؟)، الشكل (ع).

r-ع-7. المدن تحت الأرض

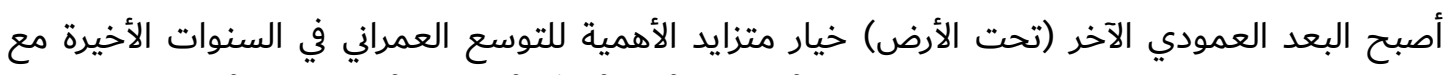

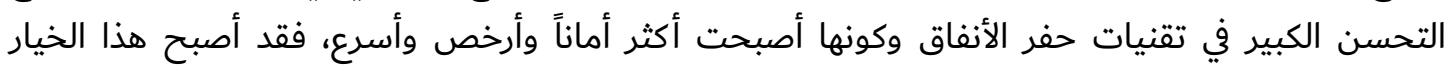

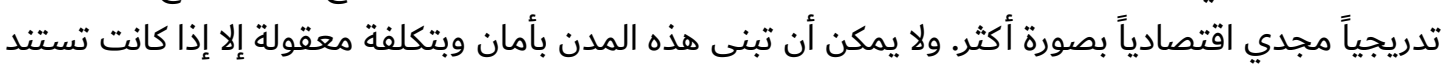
إلى فهم علمي سليم لباطن الأرض، والمعرفة اللازمة لذلك متوفرة على نطاق المان واسع فئ في المنظمات العلمية

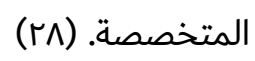




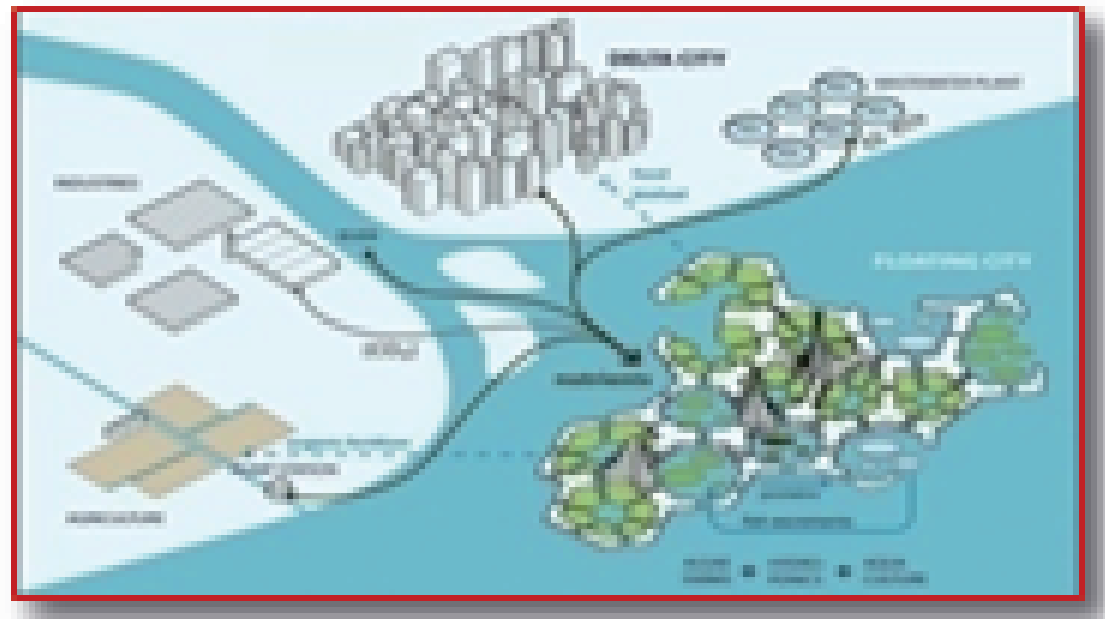

شكل ع: رسم توضيحي لفكرة المدن العائمة (rV).

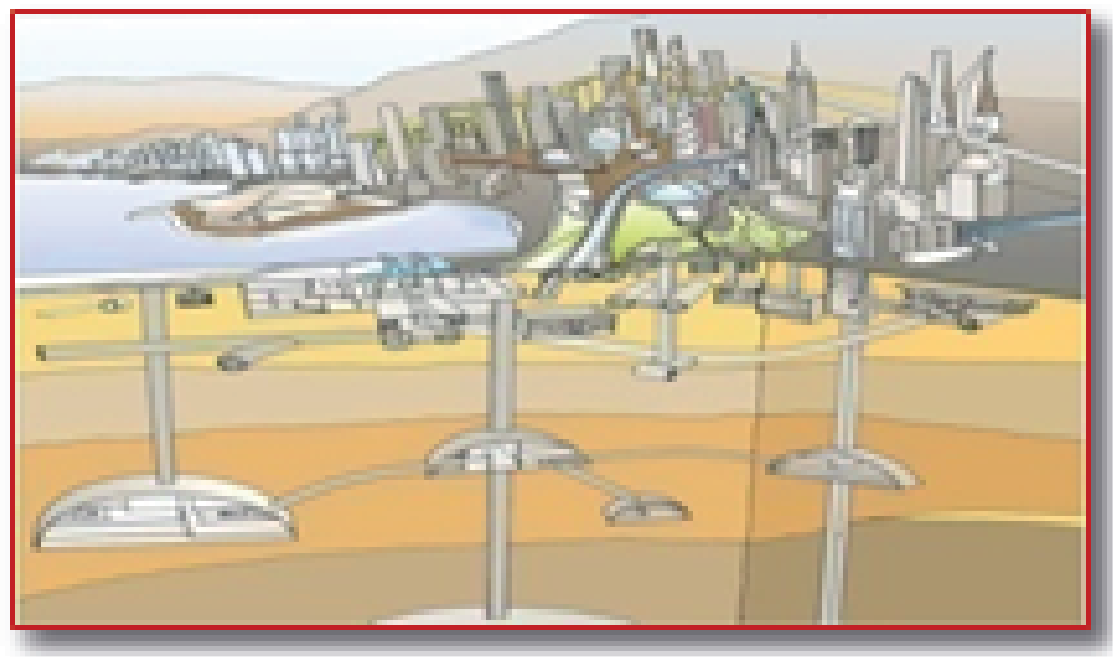

شكل 0: انطباع فنان عن مدينة تحت الأرض جزئيا بحلول نهاية القرن الحادي والعشرين (9)).

ويمثل سياسة مهمة في معالجة ندرة الأراضي الحضرية في المدن ويمكن تحديد مفهوم الإملاء بأنه عملية

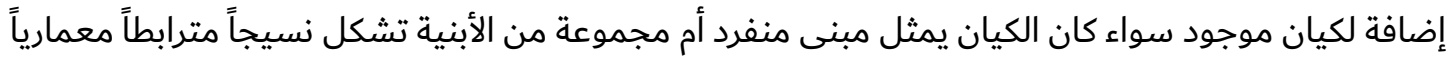

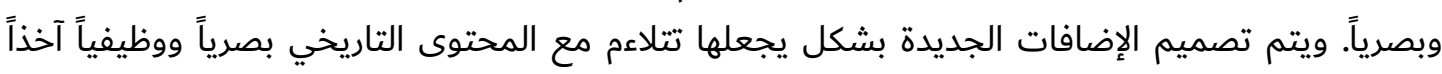

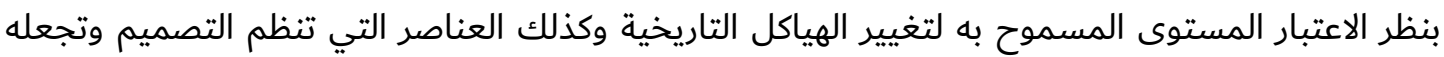
متآلفاً، والمدى الذي يمكن السماح به للاعتبارات الوظيفية بان تتقدم على تلك الاعتبارات التي تمثل التحديد الميد التاريخي والقيم الجمالية التقليدية. (•r) 


\section{r-ع-1. سياسة نقل بعض استعمالات الأرض خارج المدينة}

وهي السياسة التي تتضمن نقل بعض استعمالات الأرض خارج المدينة وذلك عندما تصبح تلك الاستعمالات

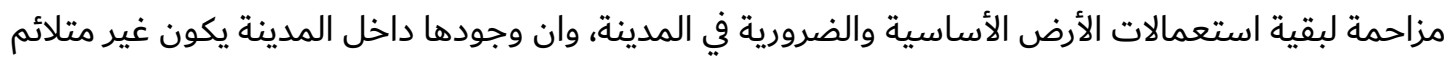

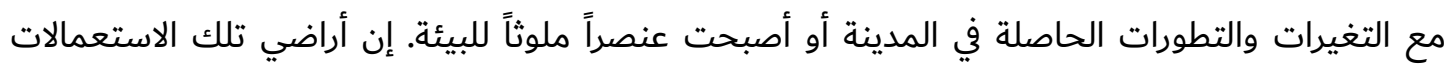

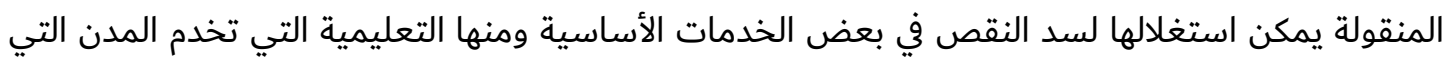
تعاني من النقص في الأراضي المخصصة لإنشائها لمواجهة النمو السكاني المتزايد بشكل مستمر.

\section{r-ع-9. المدن الذكية}

وتعني اعتماد المدن على التطور التكنولوجي لتقديم الخدمات لسكانها في كافة المجالات، وتقوم فكرتها

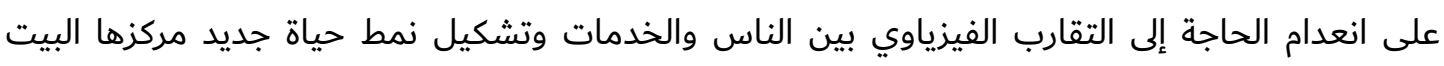

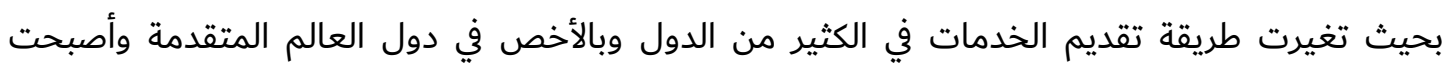
بعض الخدمات لا تحتاج لنفس مساحات الأرض الحضرية اللازمة في الظروف الاعتئ لاعتيادية. ومن ابرز المجات الإلات

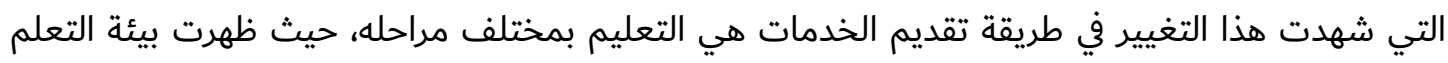

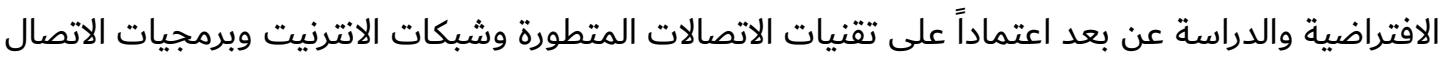

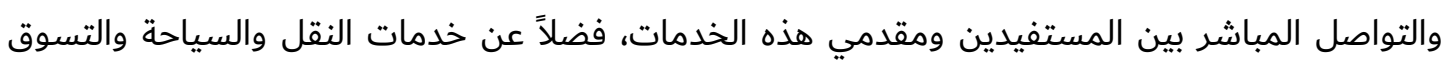
وسياسات الحكومات الالكترونية التي غيرت طريقة تعامل سكان المدن مع المؤسسات الخدمية المختلفة فذهات

\section{"ا. ندرة الأرض المخصصة للخدمات التعليمية "- ا. مفردات مشكلة ندرة الأرض المخصصة للخدمات التعليمية}

هناك جوانب عديدة خاصة بمشكلة ندرة الأرض الحضرية المخصصة للخدمات التعليمية. ويمكن تناول ثلاث مفردات رئيسة تتركز حولها هذه المشكلة الحضرية، وهي :

• أسباب ندرة الأرض المخصصة للخدمات التعليمية.

• مستويات ندرة الأرض الحضرية المخصصة للخدمات التعليمية

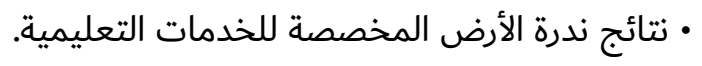

وقد أمكن استخلاص هذه المفردات من الجوانب المتداخلة التي تضمنتها الدراسات الحضرية المختلفة،

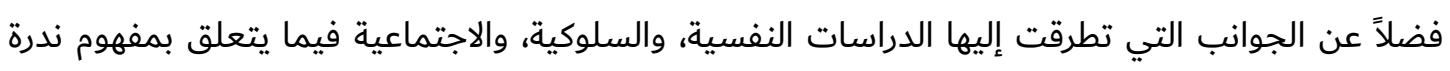

الأرض الحضرية، الشكل (7). 


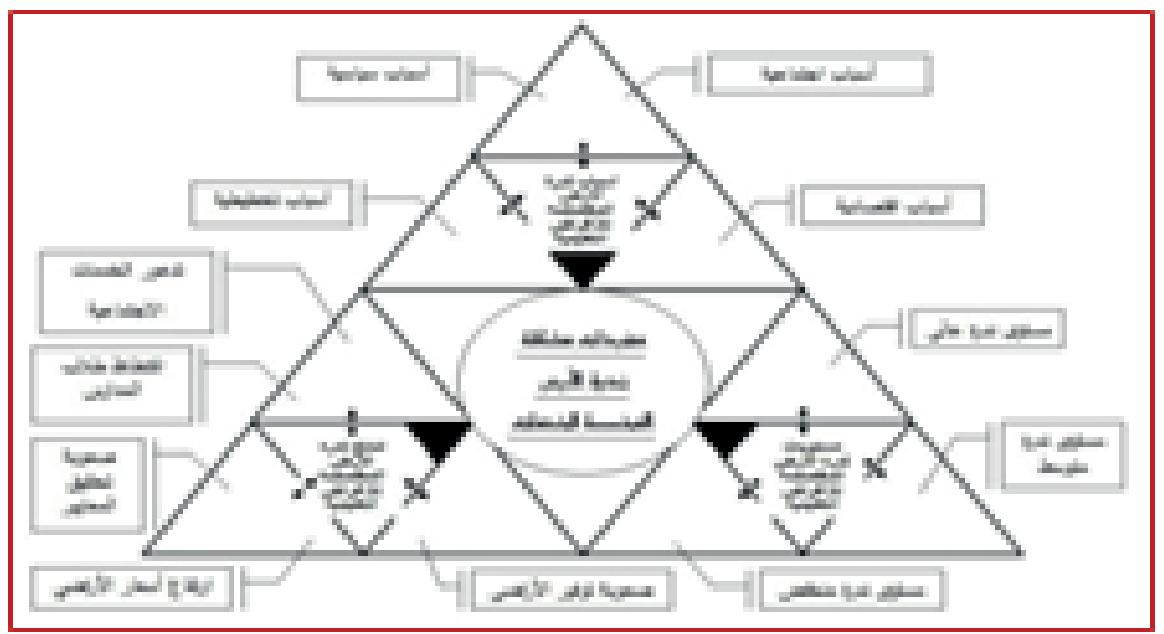

شكل 7: مفردات مشكلة ندرة الأرض المخصصة للخدمات التعليمية

ع. مستخلص الإطار النظري

ا. إن تحقيق المعايير التخطيطية في تخطيط المدينة ينتج عنه تخطيط كفوء للخدمات التعليمية والذي يؤدي بدوره إلى رضا سكان المدينة بصورة عامة عن هذه الخدمات ورضا الفئات المستفيديدة (الطلبة) من هذه الخدمات بصورة خاصة. r. إن الأرض الحضرية تتسم غالباً بالندرة وذلك للأسباب التالية : • أهميتها الكبيرة في المجال الاقتصادي والاجتماعي والسياسي. • • استمرار التحضر بشكل متسارع. • النمو المتزايد لسكان المدن.

ب.. تتطلب ندرة الأرض الحضرية اعتماد سياسات حضرية تعالج هذه الندرة بأساليب تتناسب مع طبيعة

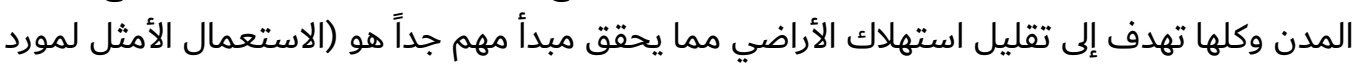

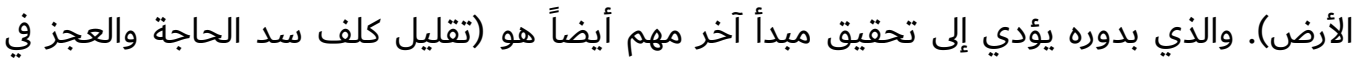

الأبنية المدرسية المطلوبة).

ع. ينتج عن تحقيق المبادئ المذكورة في النقطة () تحقيق الاستدامة في استخدام مورد الأرض. 0. مما تقدم نتج عدد من المؤشرات التي تؤثر في السياسة المعتمدة لمعالجة ندرة الأرض الحضرية

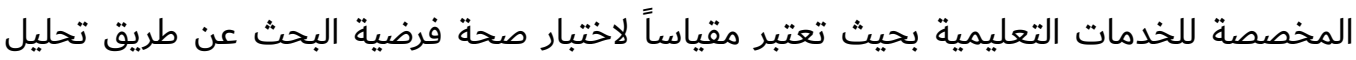

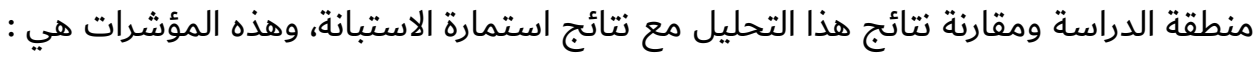

\section{• تحقيق معايير تخطيط الخدمات التعليمية. \\ • • إمكانية النمو الحضري داخل حدود المدينة. \\ • رضا المستفيدين من الخدمة التعليمية. \\ • تقليل كلف سد العجز في الخدمات التعليمية. \\ • الاستخدام الأمثل لمورد الأرض الحضرية.

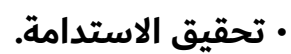


تكمن أسباب اختيار منطقة الدراسة الى كون مدينة الصدر تعاني من الاكتظاظ الطلابي في المدارس وازدواج

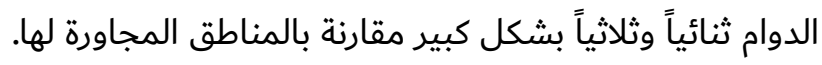

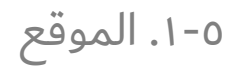

تقع مدينة الصدر في الشمال الشرقي من مدينة بغداد وتنحصر بين قناة الجيش التي تحدها من الجنوب

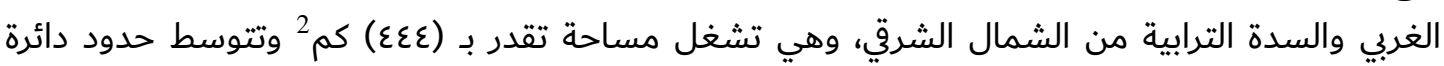

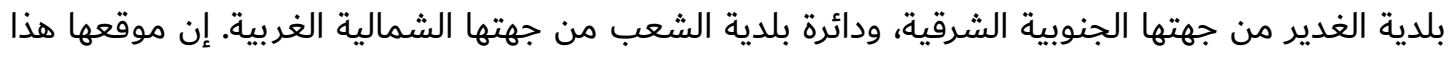

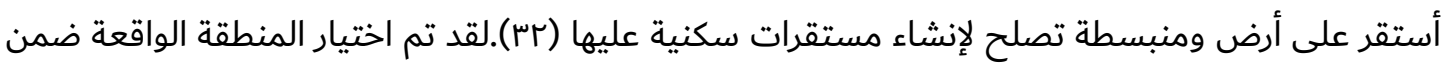

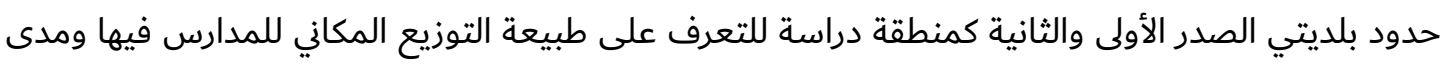

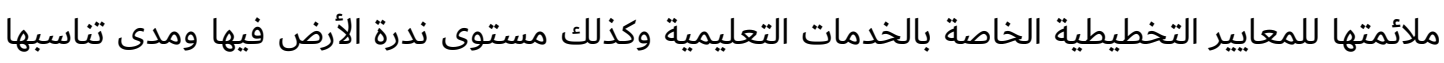

مع توزيع السكان وأعدادهم، الخريطة (V).

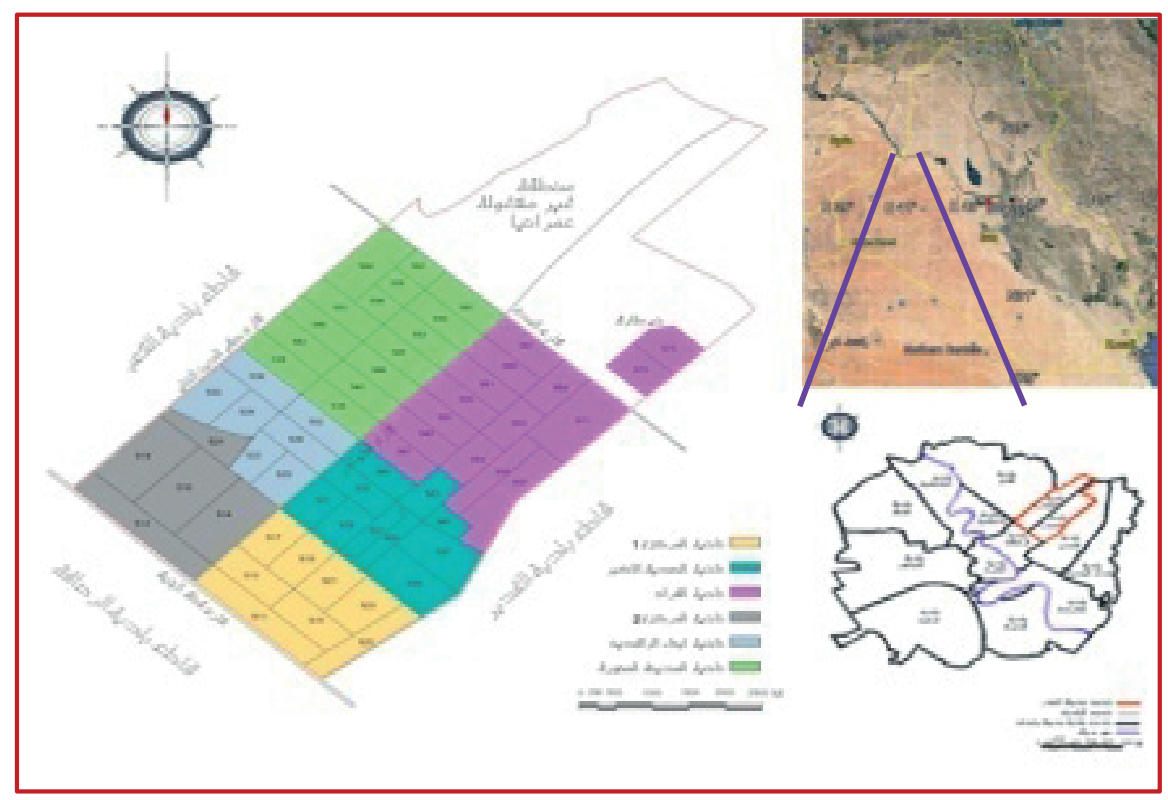

شكل V: موقع مدينة الصدر بالنسبة لمدينة بغداد والعراق (سشץ).

لقد أرتفع عدد السكان في مدينة الصدر حوالي أربعة أضعاف منذ نشوءها ولحد الآن، ففي إحصاء عام 1970 كان

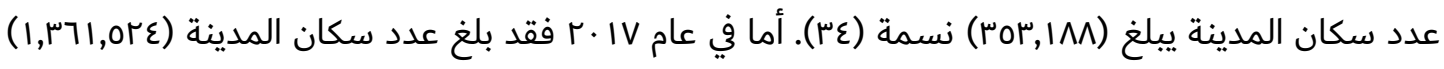

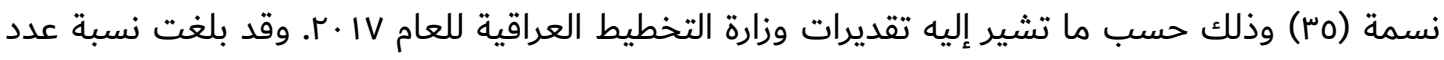

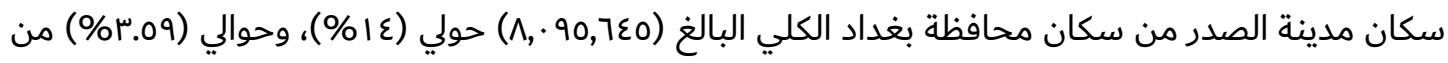

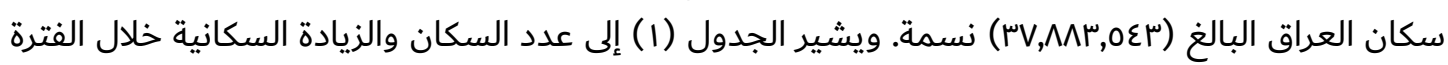


I I . IV-1970 لمدينة الصدر، حيث يشير الجدول إلى أن مدينة الصدر أصبحت مدينة مليونية منذ إحصاء عام

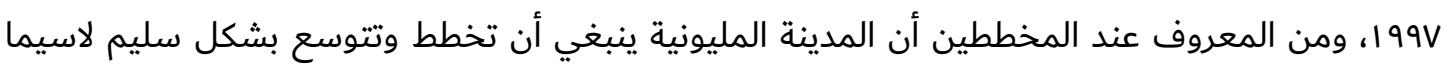
وان النمو السكاني فيها سريع وكبير.

جدول 1: عدد السكان والزيادة السكانية لمدينة الصدر (ךَ).

\begin{tabular}{|c|c|c|}
\hline الزيادة السكانبة (نسمة) & عدد السكان (نسمة) & السنة \\
\hline-- & 353,188 & 1967 \\
\hline 29,768 & 682,956 & 1977 \\
\hline 162,131 & 845,087 & 1987 \\
\hline 188,863 & $1,033,950$ & 1997 \\
\hline 212,432 & $1,246,382$ & 2012 \\
\hline 115,142 & $1,361,524$ & 2017 \\
\hline
\end{tabular}

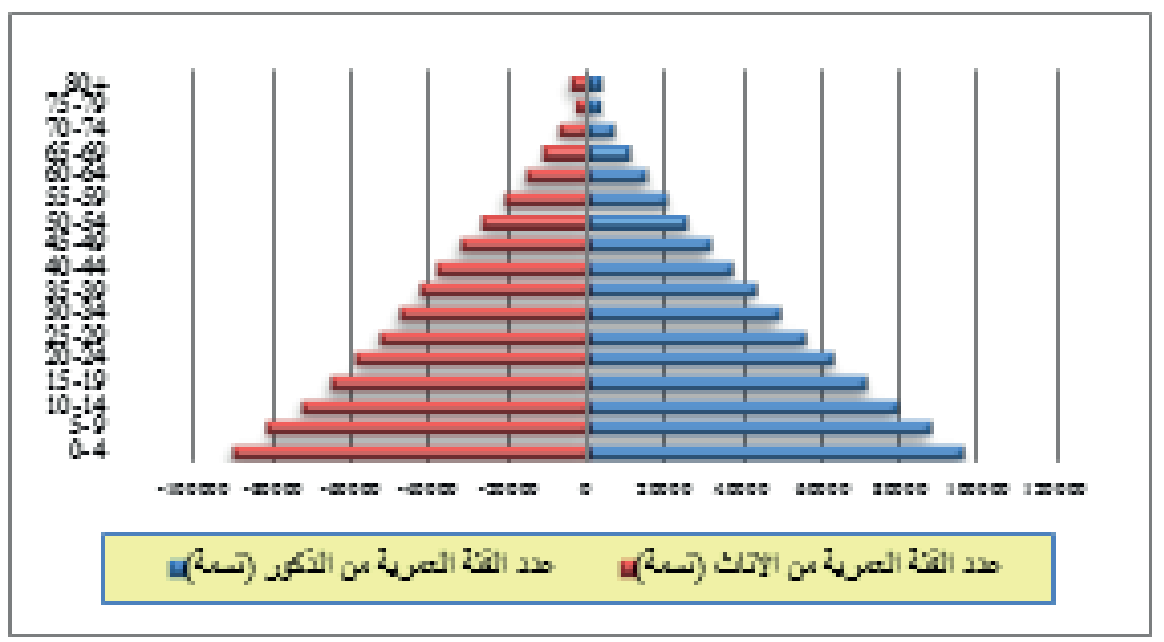

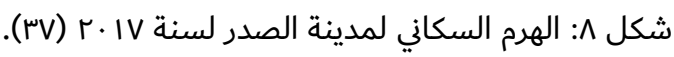

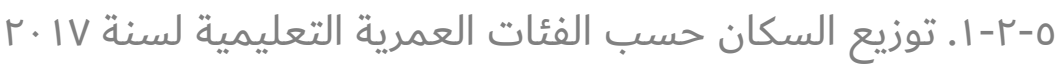

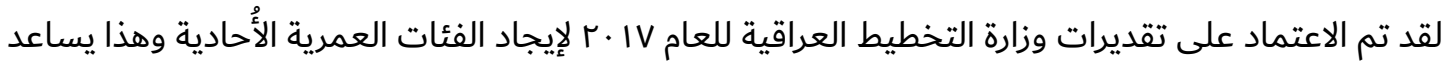

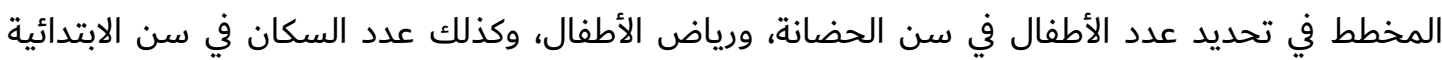

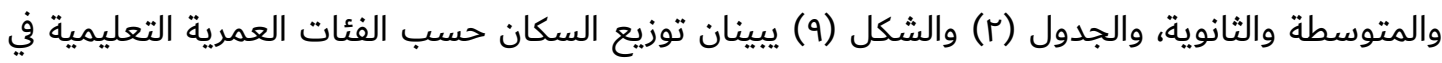

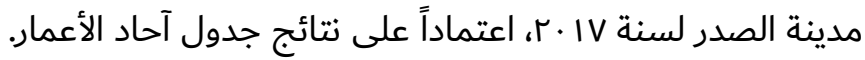

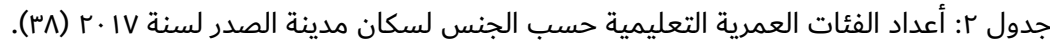

\begin{tabular}{|c|c|c|c|c|}
\hline (نسمة) & عدد الإناث) & عدد الأكور & الفئة العمرية & التعليمية \\
\hline 70,793 & 34,311 & 36,482 & $5-4$ & رياض الأطفال \\
\hline 205,62 & 94,377 & 111,35 & $11-6$ & الابتدائية \\
\hline 88,847 & 42,671 & 46,175 & $14-12$ & المتوسطة \\
\hline 83,506 & 40,152 & 43,354 & $17-15$ & الإعدادية \\
\hline
\end{tabular}




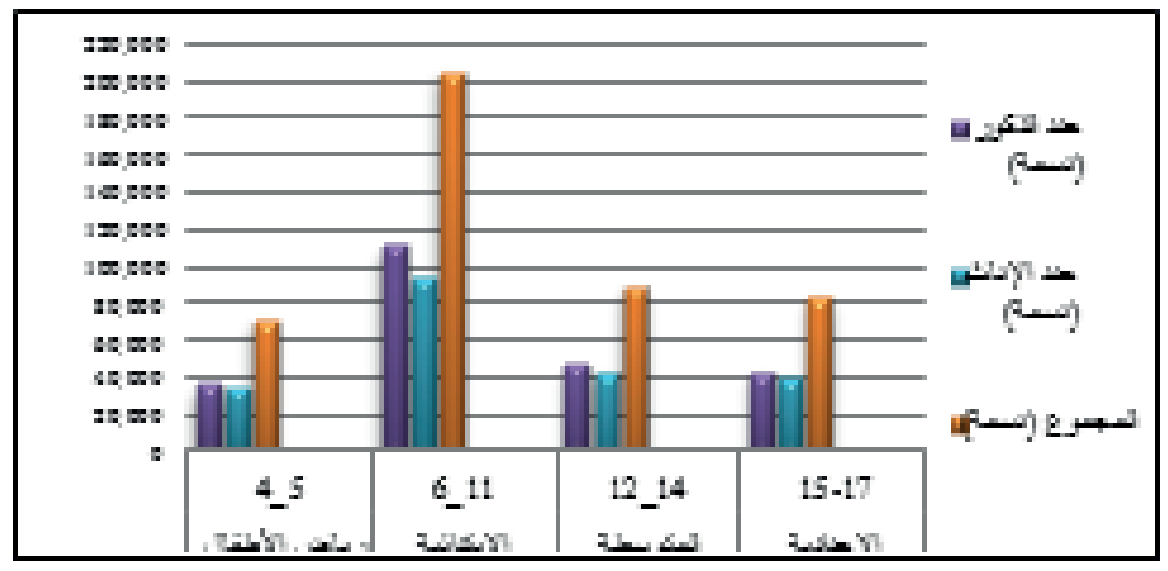

شكل 9: أعداد الفئات العمرية التعليمية حسب الجنس لسكان مدينة الصدر لسنة IV · م (q).

\section{7. الخدمات التعليمية في مدينة الصدر}

7-1. واقع حال الخدمات التعليمية في مدينة الصدر

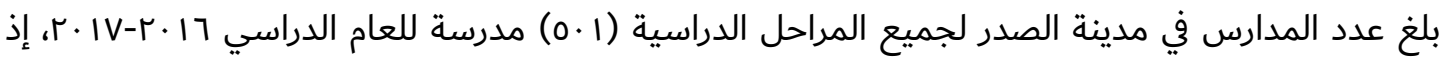

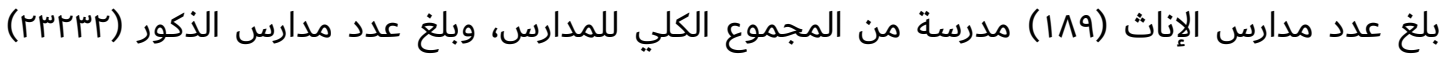

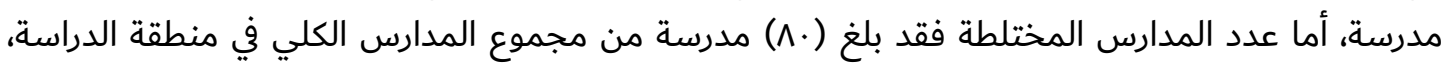

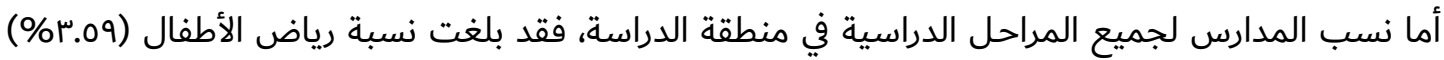

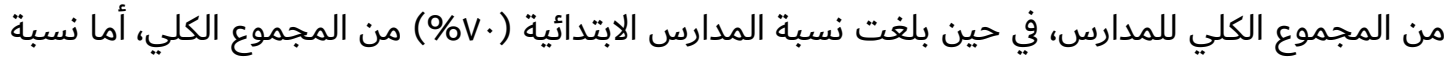
المدارس المتوسطة فقد بلغت (7/7\%)، وقد بلغت نسبة المدارس الإعدادية (7\%)، والمدارس (الثانوية)

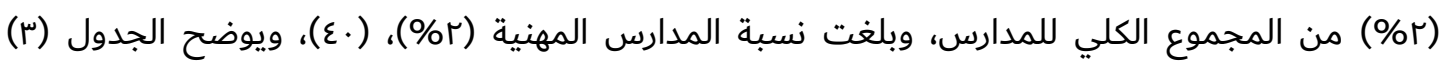

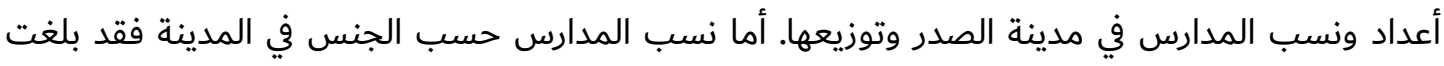

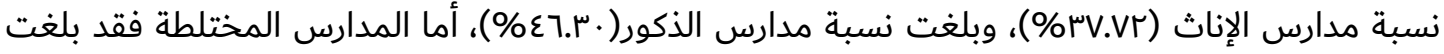
(0.97\%) من مجموع المدارس.

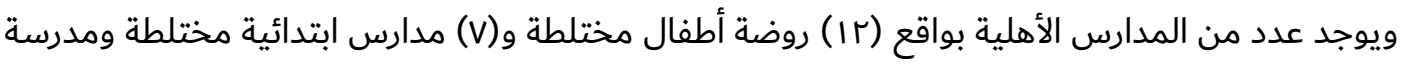
متوسطة واحدة للبنات وإعدادية واحدة للبنات أيضاً وأخرى ثانوية للبنين.

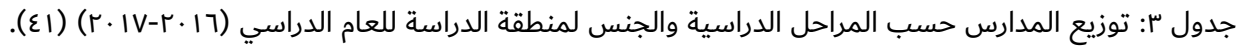

\begin{tabular}{|c|c|c|c|c|}
\hline المجموع & المختلط & الإناث & الذكور & الدراسية المرحلة \\
\hline 18 & 18 & --- & --- & رياض الأطفال \\
\hline 351 & 62 & 134 & 155 & الابتدائية \\
\hline 82 & -- & 33 & 49 & المتوسطة \\
\hline 31 & -- & 14 & 17 & الإعدادية \\
\hline 12 & -- & 6 & 6 & الثانوية \\
\hline 7 & -- & 2 & 5 & المهني \\
\hline 501 & 80 & 189 & 232 & المجموع \\
\hline
\end{tabular}

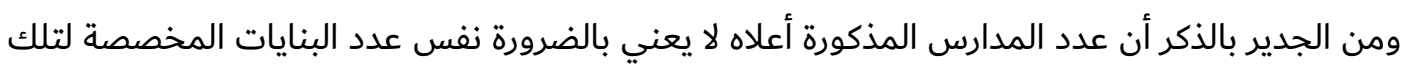

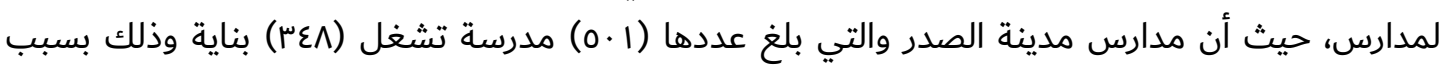


عدم توفر البنايات اللازمة لأسباب مختلفة من أبرزها ندرة الأراضي الشاغرة في المدينة، ونتيجة لذلك برزت

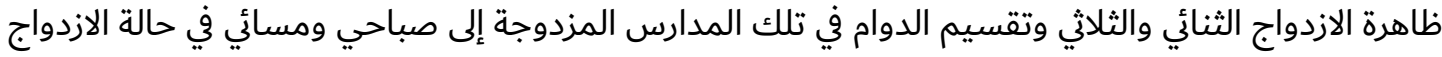

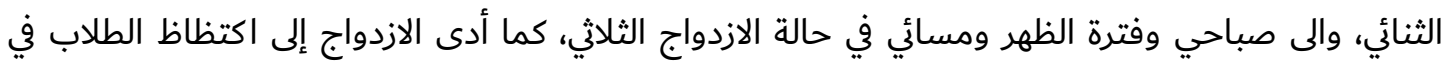
الصفوف والمدارس.

7-r. تقييم مستوى تخطيط الخدمات التعليمية لمدينة الصدر

سيتم الاعتماد على المقارنة بين واقع الحال من جهة والمعايير الكمية للخدمات التعليمية المعتمدة من جهة أخرى وذلك للمؤشرين (طالب / مدرسة)، (طالب / مدرس)، الجدول (ع) : جدول ع: تقييم الخدمات التعليمية للمراحل الدراسية في مدينة الصدر (rع).

\begin{tabular}{|c|c|c|}
\hline الفرق بين المعيار وواقع الحال & المعيار & المرحلة الدراسية \\
\hline $208-$ & طفل / روضة & \multirow{2}{*}{ رياض الأطفال } \\
\hline $56-$ & طقل / شعبة & \\
\hline $90-$ & تلميذ / مدرسة & \multirow{2}{*}{ الابتدائية } \\
\hline 6- & تلميذ / شعبة & \\
\hline $251-$ & طالب / مدرسة & \multirow{2}{*}{ المتوسطة } \\
\hline $9-$ & طالب / شعبة & \\
\hline $424-$ & طالب / مدرسة & \multirow{2}{*}{ الإعدادية } \\
\hline $7-$ & طالب / شعبة & \\
\hline $402-$ & طالب / مدرسة & \multirow{2}{*}{ الثانوية } \\
\hline $15-$ & طالب / شعبة & \\
\hline $141+$ & طالب / مدرسة & \multirow{2}{*}{ المهنية } \\
\hline $14+$ & طالب / شعبة & \\
\hline
\end{tabular}

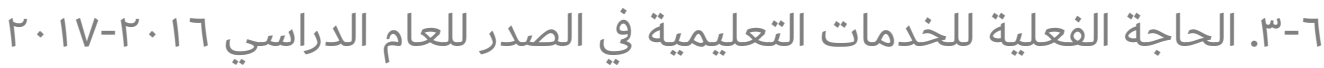
بعد تحديد عدد المدارس الموجودة في مدينة الصدر من خلال القائمة الموقعية للمدارس للعام الدراسي

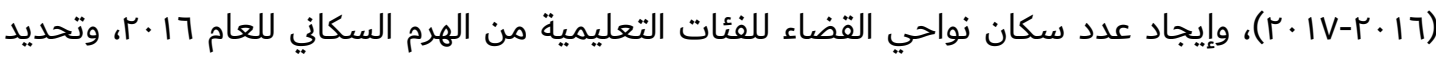

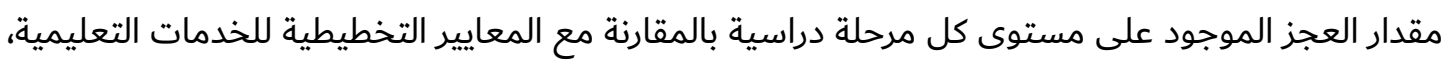
تم تحديد الحاجة الفعلية لمنطقة الدراسة من الخدمات التعليمية للمراحل الدراسية، الجدول (o).

جدول 0: الحاجة الفعلية للخدمات التعليمية في مدينة الصدر للعام IV.r.

\begin{tabular}{|c|c|c|c|}
\hline الفعلية & (المعيار التخطيطي) & عدد المدارس (واقع الحال) & المرحلة الدراسية \\
\hline 21 & 39 & 18 & رياض الأطفال \\
\hline 68 & 419 & 351 & الابتذائية \\
\hline 48 & 130 & 82 & المتوسطة \\
\hline 41 & 72 & 31 & الإعدادية \\
\hline 9 & 16 & 7 & الثانوية \\
\hline
\end{tabular}




\section{V. معالجة ندرة الأرض الحضرية في منطقة الدراسة}

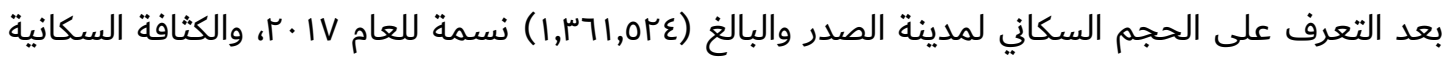

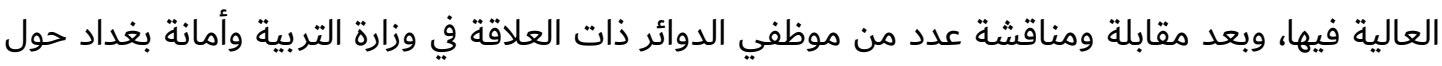

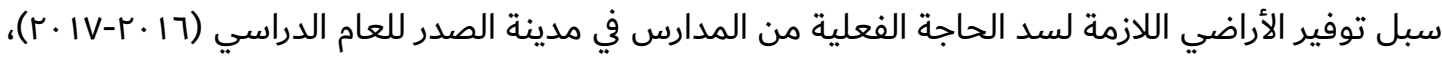

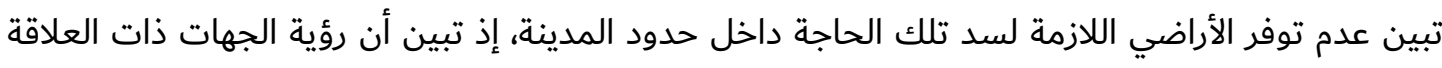

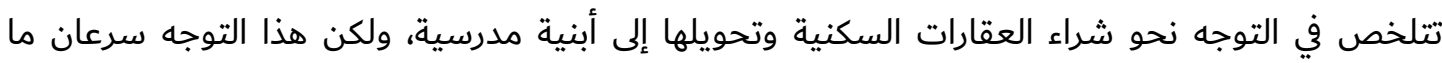

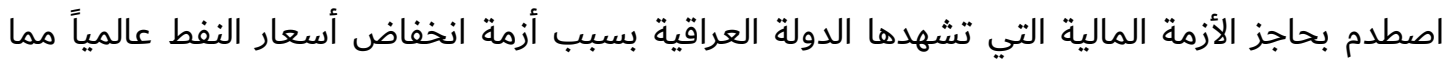

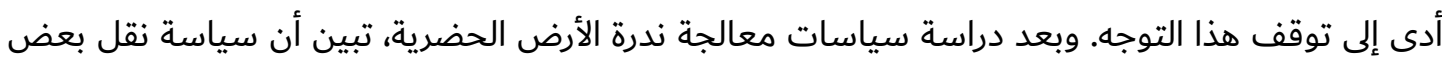

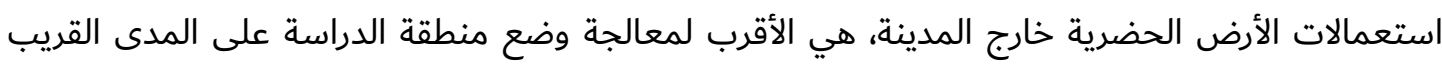

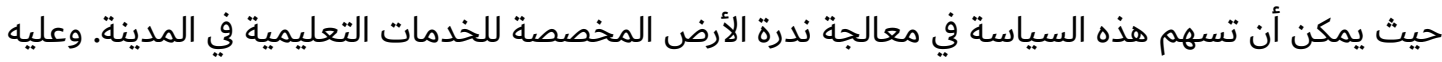

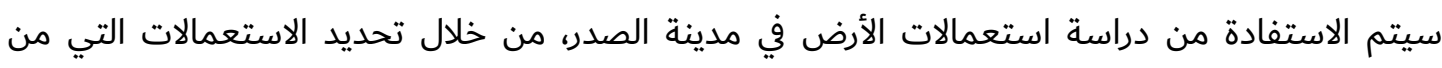

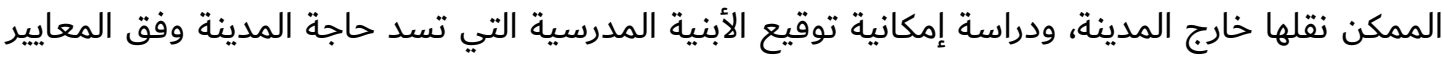

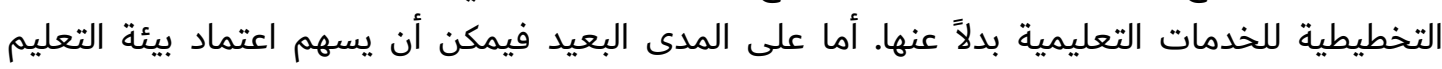

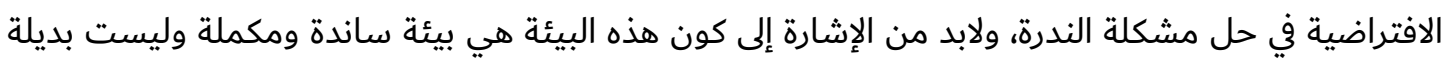
للبيئة التعليمية التقليدية.

\section{| I-V المعالجة ندرة الأرض الحضرية المخصصة للخدمات التعليمية في منطقة الدراسة}

بعد ما تبين عدم إمكانية نمو مدينة الصدر خارج حدود المدينة الحالية، ستتم معالجة مشكلة ندرة الأرض المات المخصصة للخدمات التعليمية في مدينة الصدر على مستويين، هما كما يأتي:

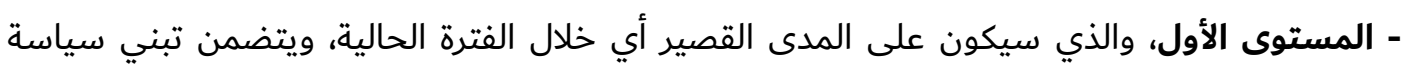

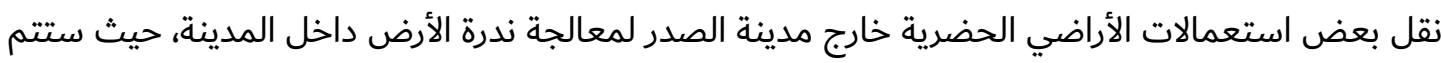

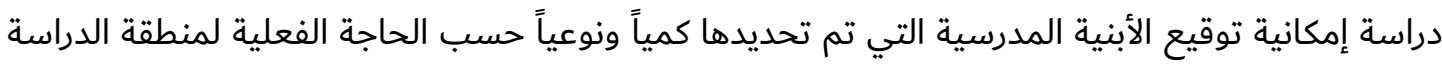

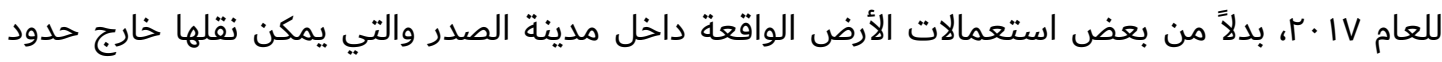

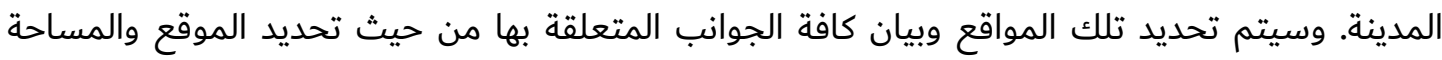
والايجابيات والسلبيات لكل منها، الشكل ( • ().

حيث يقترح الباحث نقل مواقع بعض استعمالات الأرض الحالية خارج المدينة، وتلك المواقع هي :

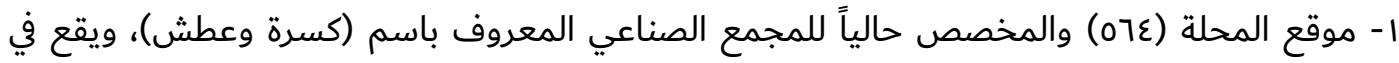

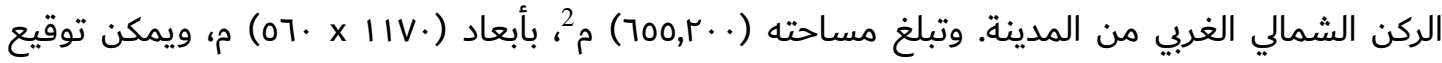
البانية المدرسية فيه لتخدم الجهة الشمالية الغربية للمدينة، الشكل (11).

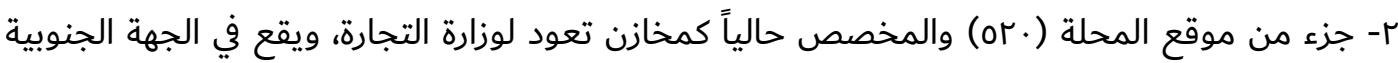

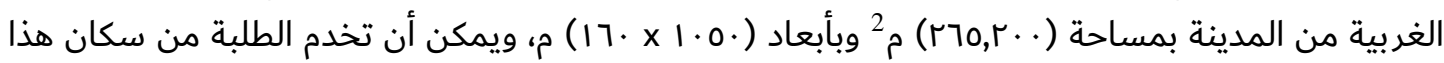
الجزء من المدينة، الشكل (r) (I). 


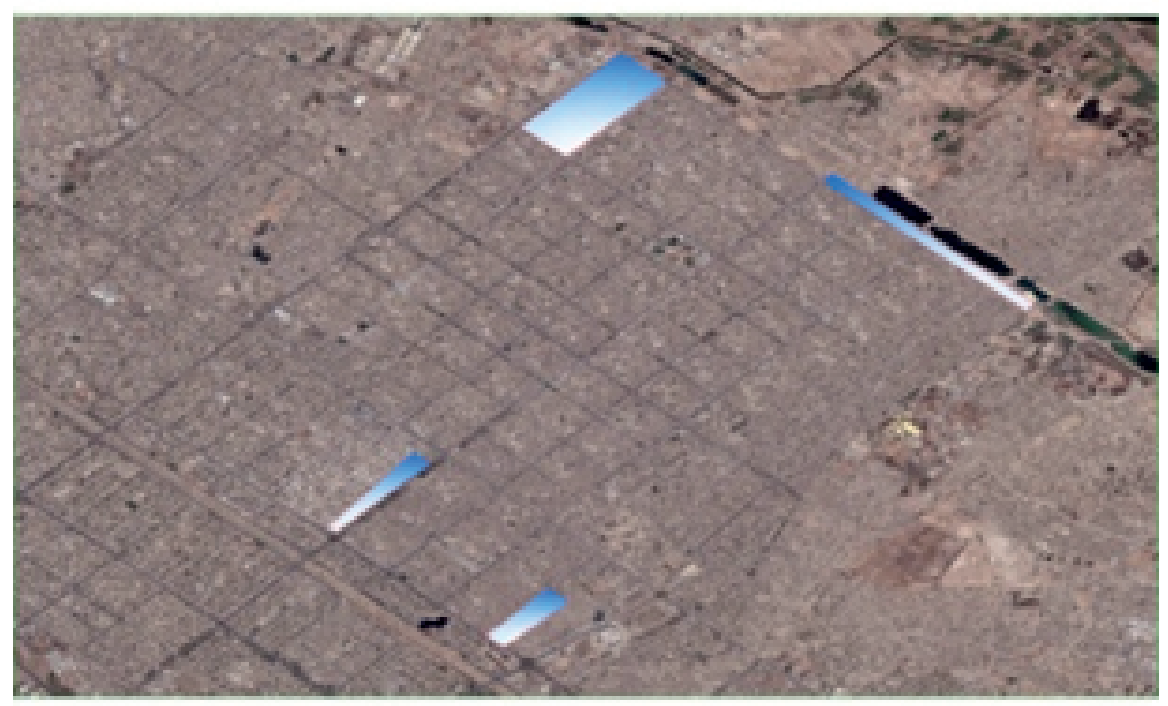

شكل · ا: المواقع المقترح نقل استعمالاتها الحالية خارج المدينة.

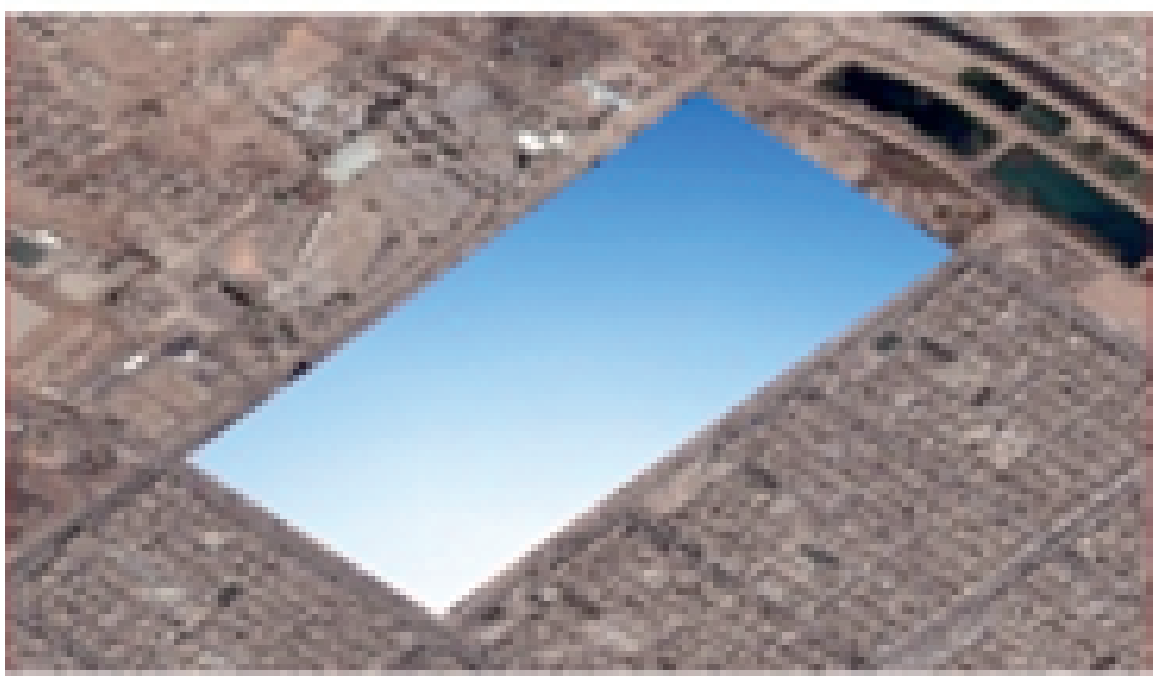

شكل 11: - موقع كسرة وعطش

بـ- جزء من موقع الشريط المحاذي للسدة الترابية وهو ارض خالية حالياً، والتي تشكل شريطاً محاذياً

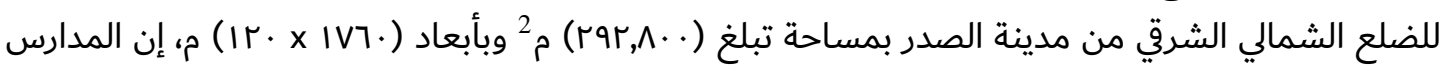

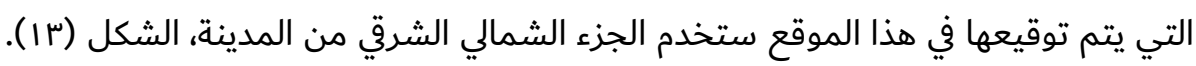

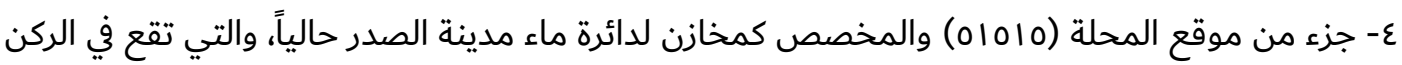

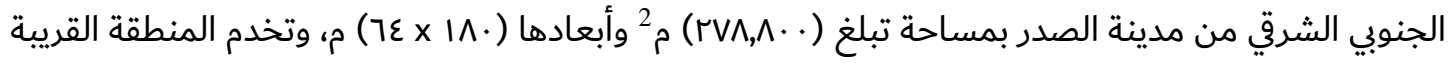
منها في الجزء الجنوبي الشرقي من المدينة، الشكل (عاعة). وقد تم اختيار تلك المواقع للأسباب الآتية :

أ- عدم تأثر المدينة بنقل مواقع تلك الاستعمالات إلى مواقع بديلة خارج المدينة. 


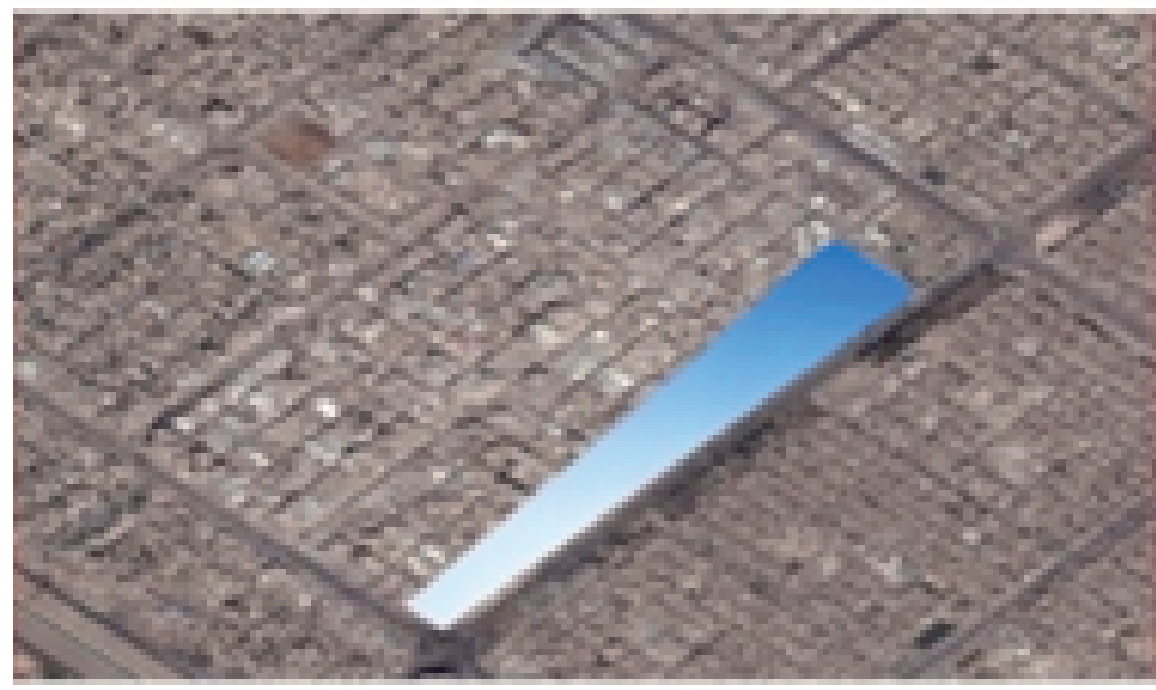

شكل rir إ: موقع المخازن.



شكل ऍ1 : موقع السدة الترابية.

ب- وقوعها في الأطراف الأربعة للمدينة مما يعزز إمكانية توزيع الخدمات التعليمية على كافة أجزاء منطقة الدراسة بشكل متوازن.

ت- أنها لا تحتاج كلف كبيرة لنقلها خارج المدينة وهو ما يكتسب أهمية كبيرة وفق نظرية العتبات، لأن تلك المواقع الأربعة المذكورة لا تحتوي على بنايات صعبة التفكيك، إذ يتكون كل من من مواقل إنع كسرة

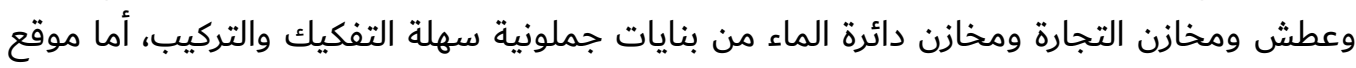
شريط السدة فإنه أرض شاغرة ولا يحتاج لأي كلف إضافية ومخارن دائرة الماء منائات جملون

- المستوى الثاني، والذي سيكون على المدى الطويل أي يمكن تنفيذه خلال السنوات القادمة، ويتضمن

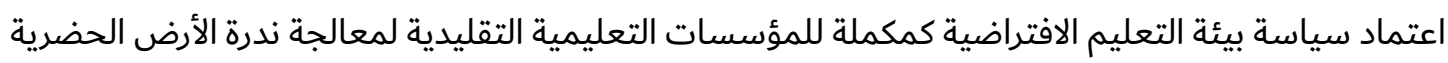




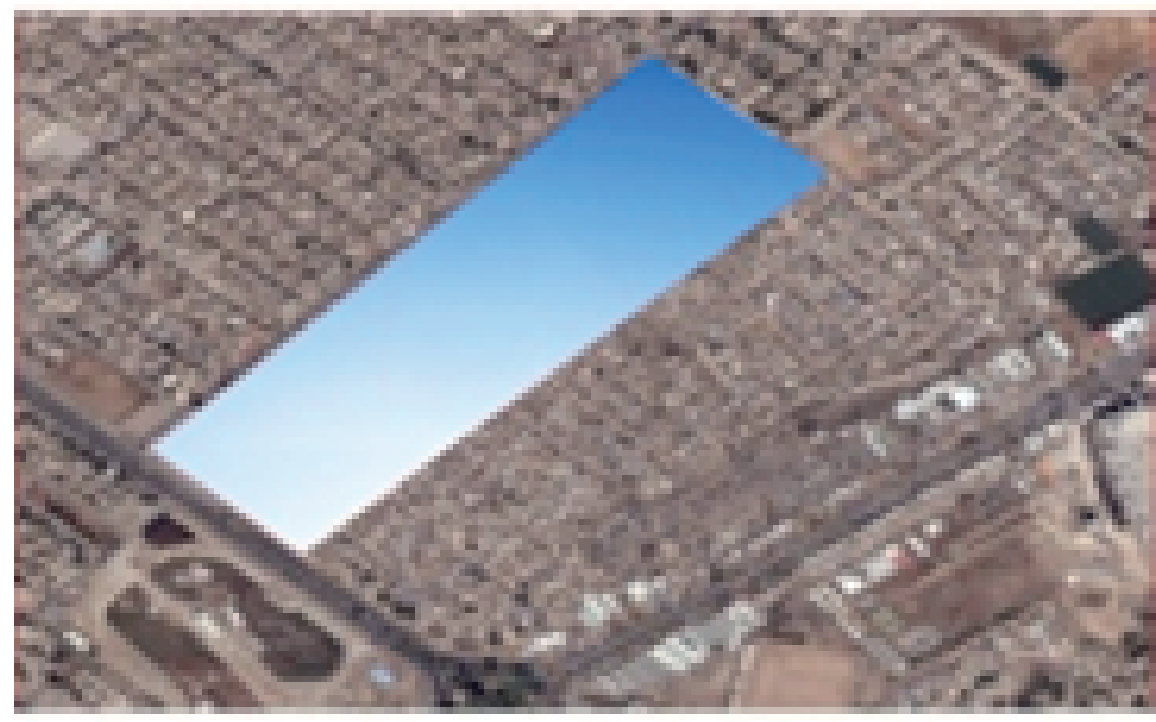

شكل ع ا: موقع مخازن دائرة الماء

المخصصة للخدمات التعليمية في مدينة الصدر، وذلك للاستفادة من التطورات التكنولوجية الهائلة وخدمة

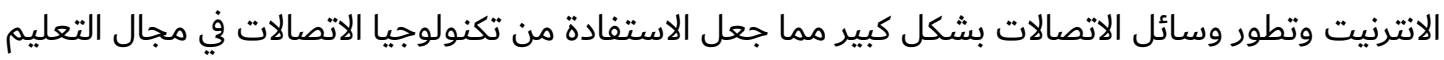
تصبح ضرورة وحتمية تاريخية لابد من اعتمادها. وستتم الاستفادة من تطور البنية التحتية مؤخراً لمنطقة

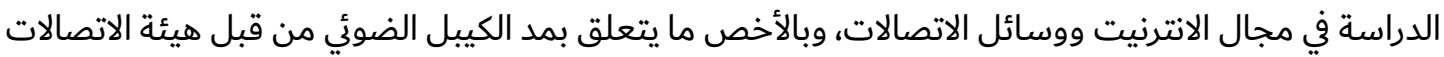

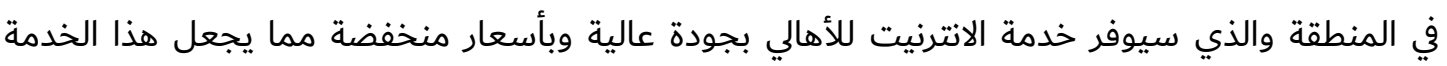
متاحة لفئات مجتمع منطقة الدراسة.

\section{^. تحليل المؤشرات من خلال دراسة وتحليل منطقة الدراسة}

ا. إمكانية النمو الحضري داخل حدود المدينة: سيتم نمو منطقة الدراسة وسد الحاجة الفعلية للخدمات

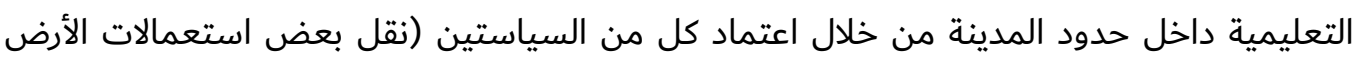

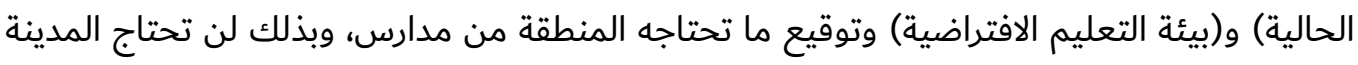
في الوقت الحالي إلى الامتداد خارج حدودها.

r. تحقيق معايير تخطيط الخدمات التعليمية: لتحقيق هذا المؤشر قدر الإمكان بالنسبة لسياسة (نقل

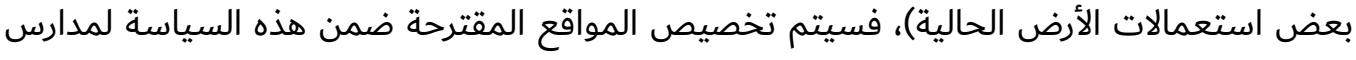

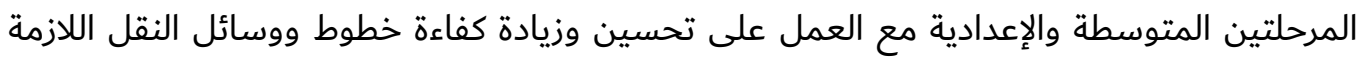

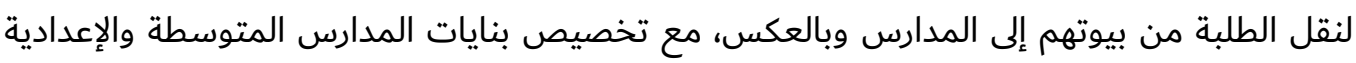

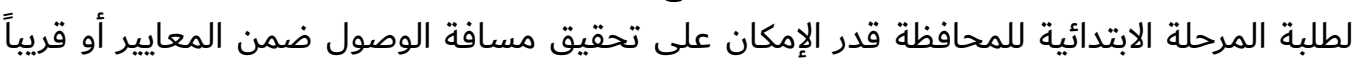

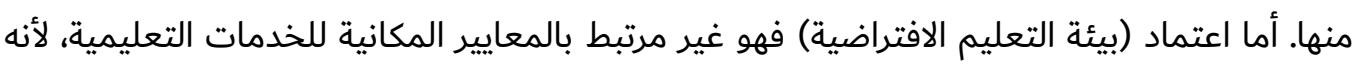
يلغي البعد المكاني لتقديم تلك الخدمات. 
بّ. تقليل كلف سد العجز في الخدمات التعليمية: إن نقل الاستعمالات المقترحة لا تحتاج إلى كلف كبيرة

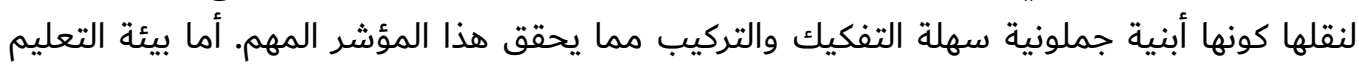

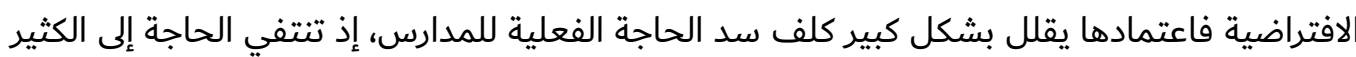
من متطلبات الأبنية المدرسية والتي تعتبر المستهلك الأكبر لميزانية التعليم. ع. الاستخدام الأمثل لمورد الأرض الحضرية: تحقق كل من السياستين مبدأ الاستخدام الأمثل لمورد

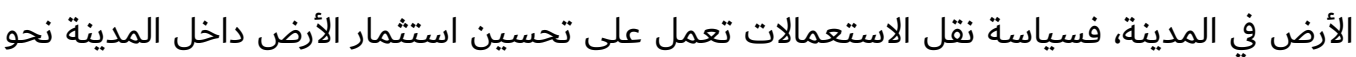

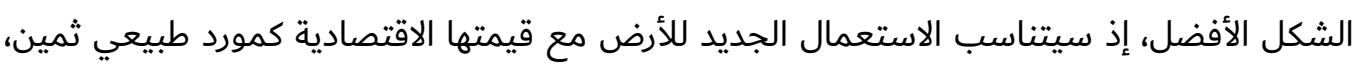

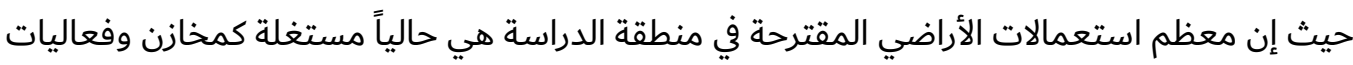

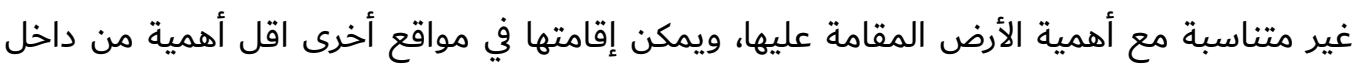

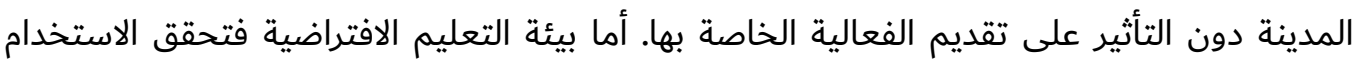

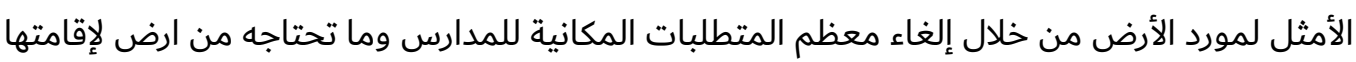

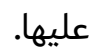

0. رضا المستفيدين من الخدمات التعليمية: يتحقق رضا المستفيدين من الخدمات التعليمية باعتماد

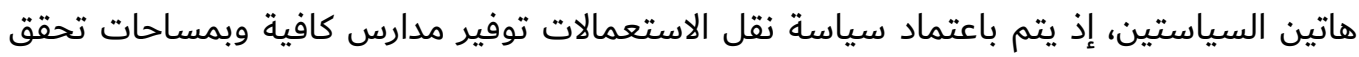

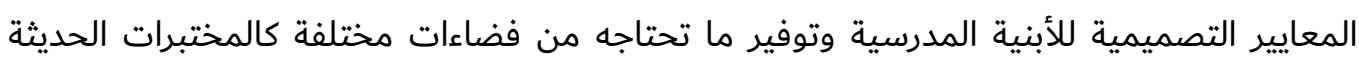

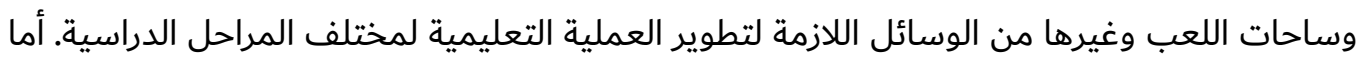
بيئة التعليم الافتراضية فتحقق رضا المستفيدين من الخدمة التعليمية باعتبارها بيئة مكملة للبيئة

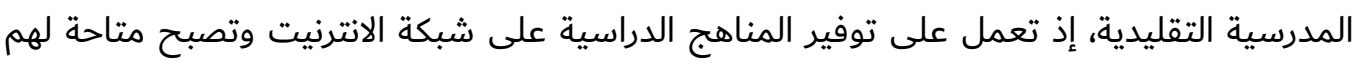

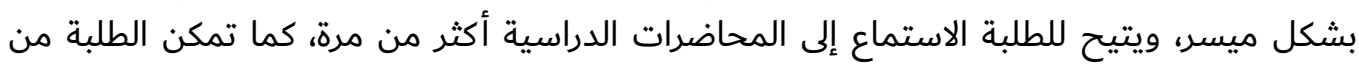

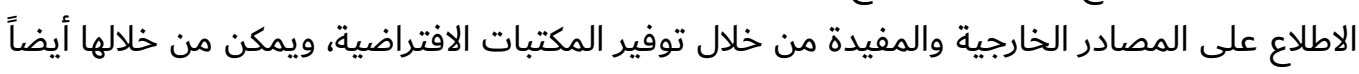

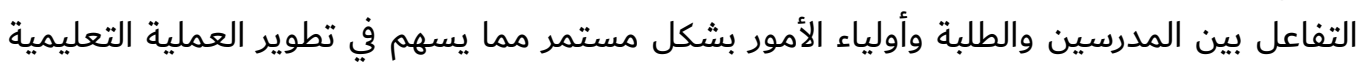
بشكل كبير.

7. تحقيق الاستدامة: إن هذا المؤشر يتحقق باعتماد كل من السياستين، ففي سياسة نقل الاستعمالات سيتم مثلاً نقل موقع (كسرة وعطش) الصناعي بعيداً عن المناطق السكنية الملاصقة له اله حالياً مما يقلل من تعرض سكان منطقة الدراسة للتلوث والضوضاء الناتجة من هذا الحي الصناعي، كما يمكن المناعن المناء

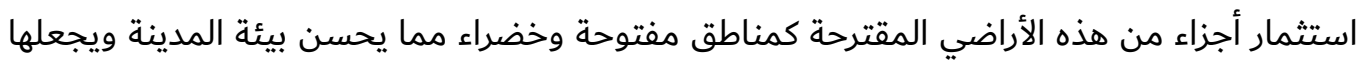

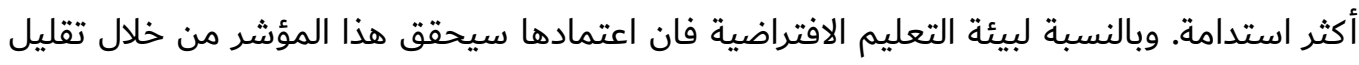

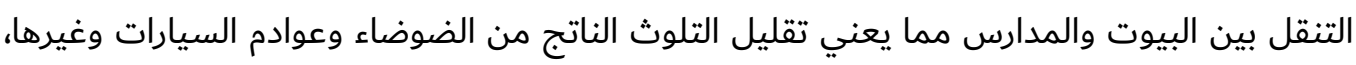
كما ستعمل على تحقيق الاستدامة من خلال استثمار الأراضي وزيادة المساحات الخضات من الخراء الخئ واستعمالات أخرى تحسن بيئة المدينة الحالية.

ا. تشهد منطقة الدراسة (10 I ) حالة ازدواج في الدوام، وهو يمثل الفرق بين عدد المدارس وعدد الأبنية

المدرسية. r. هناك عجز في الخدمات التعليمية في منطقة الدراسة ولكافة المراحل الدراسية. 
"ّ. من خلال تحليل نطاق الخدمة لجميع المراحل الدراسية وحسب المعايير المعتمدة لنصف قطر نطاق

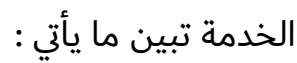

ع. توجد مساحة كبيرة من منطقة الدراسة لا تقع ضمن نطاق الخدمة لمرحلتي رياض الأطفال والمدارس المهنية بسبب التوزيع المكاني لكل منهما في منطقة منطة الدراسة.

0. بالنسبة لبقية المراحل الدراسية فنجد أن نطاق الخدمة للمدارس يتداخل في أغلب الأحيان، وكذلك لا

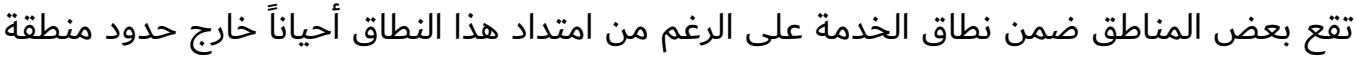
الدراسة وذلك لمحدودية المساحة والكثافة السكانية العالية.

7. إن اعتماد سياسة (نقل بعض استعمالات الأرض الحضرية خارج المدينة) على المدى القريب في

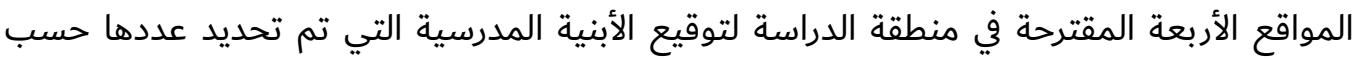
الحاجة الفعلية وفقاً للمعايير، يعتبر أفضل الخيارات بالمقارنة مع بقية السياسات الحضرية الانية المدرسية

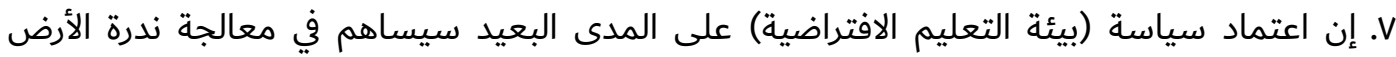

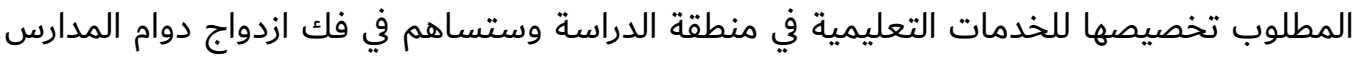
وسد الحاجة الفعلية المستقبلية من الأبنية المدرسية. ^. إن اعتماد السياستين المذكورتين في أعلاه يساعد في تحقيق الاستدامة في استخدام مورد الأرض وبنسب جيدة بالمقارنة مع بقية السياسات الحضرية.

ا. السعي لفك الازدواج في الدوام الحاصل في كثير من المدارس لمنطقة الدراسة، من خلال بناء المدارس

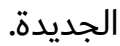

r. العمل على سد العجز والحاجة الفعلية على مستوى الخدمات التعليمية في كافة النواحي لمنطقة الدراسة تبعاً لمعايير تخطيط تلك الخدمات.

".. اعتماد برمجيات نظم المعلومات الجغرافية (GIS) لعمل الخرائط وتهيئة البيانات المحدثة بشكل دوري والتوزيع المكاني للخدمات التعليمية.

ع. التنسيق بين وزارة التربية والجهات ذات العلاقة لتطبيق سياسة (نقل بعض استعمالات الأرض خارج

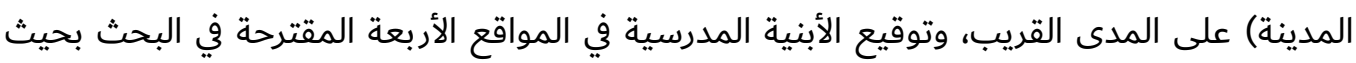

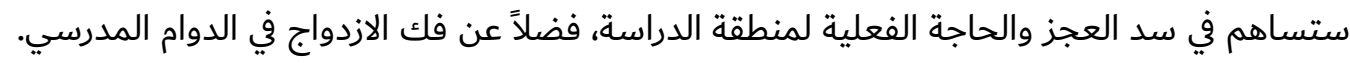

0. التنسيق بين وزارة التربية والجهات ذات العلاقة لتطبيق سياسة (بيئة التعليم الافتراضية) على المدى

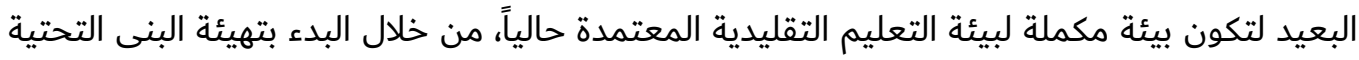

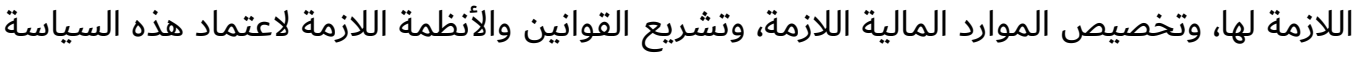

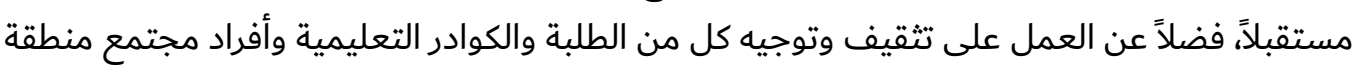

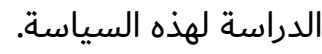


[1] احمد، محمد شهاب، ومؤمل علاء الدين، "المتطلبات الفضائية لتخطيط المدينة"، مطبعة التعليم العالي،

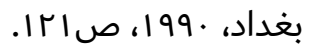

[r] الديوجي، ممتاز وآخرون، "اثر التغيرات المورفولوجية في النسيج الحضري على خصائصه التركيبية"،

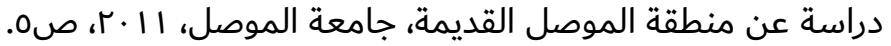

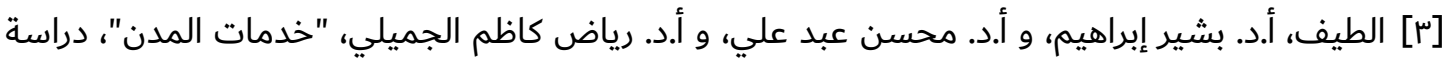

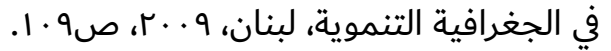

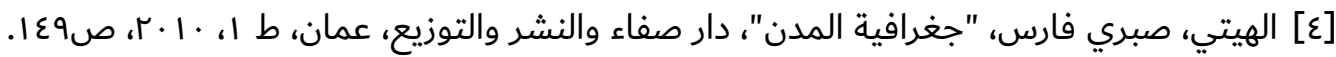

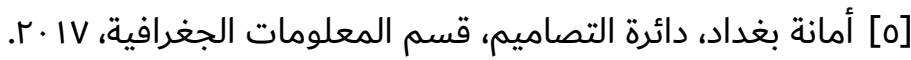
[7] شقير، هبة محمد حمودة، "توزيع وتخطيط الخدمات التّعليمية في محافظة سلفيت"، رسالة ماجستير،

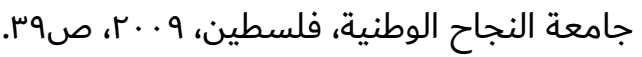
[V] [لر الرزاق، نجيل كمال، ونغم فيصل، "كفاءة توزيع الخدمات التعليمية في منطقة الاعظمية"، مجلة

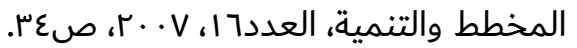

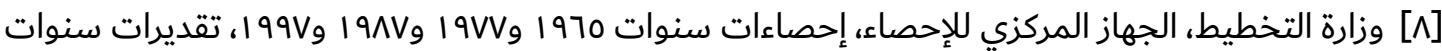
$r \cdot r \cdot \ln \cdot r \cdot 14$

[9] وزارة التربية، المديرية العامة لتربية بغداد، الرصافة/\%، قسم التخطيط التربوي، شعبة الإحصاء، IV. [T.

[10] Arbury, Joshua,"From Urban Sprawl to Compact City - An Analysis of Urban Growth Management in Auckland", postgraduate studies, Auckland University, 2008, P44.

[11] De Castro, Paolo,"The Politics of Land and Food Scarcity", 1st edition, Routledge, 2013, P92.

[12] De Graaf, Rutger,"Adaptive urban development, A symbiosis between cities on land and water in the 21st century", 1st edition, Rotterdam University, Netherland, 2012, $P_{9}, P_{10}, P_{12}, P_{19}, P_{21}$

[13] Divjak, Mojca Sasek,"Sustainable Aspects of Urban Renewal", Slovenia, 2001, P123.

[14] Etingoff, Kimberly,"URBAN ECOLOGY, Strategies for Green Infrastructure and Land Use", Apple Academic Press, 2016, P293.

[15] Fischer, G.,"Scarcity and abundance of land resources", FAW Report, 2010, P46.

[16] Evans, Alan W.," Economics and Land Use Planning", 1st Edition, India,2004, P117.

[17] Gosling, D.,"Maitland, B; Concepts of urban design", St. Martin's press, UK, 1984, P47.

[18] Hongjie, Xie \& Ming, Chen," Toward a Compact Settlement, A Sustainable Development way of Settlements for Chinese City", International Conference, Wuhan, China, 2009, P2.

[19] Kivell, Philip," LAND AND THE CITY, Patterns And Processes Of Urban Change", 1st Edition, routledge, USA, 1993, P6, P9. 
[20] Kraas, Frauke and Others,"Megacities, Our Global Urban Future", Springer Science +Business Media B.V., 2014, P25, P31-34.

[21] Lappia, J.H., I. van den Donker and M. Bedeker,"Innovation for Sustainability, Universidade Lusíada, Porto, Portugal", 2012, P27-29, P28.

[22] Tully and Others, Peggy,"Modern American housing", Princeton Architectural Press,USA, 2013, P237.

[23] Vandermeulen, Valerie and Others,"PERCEPTION OF LAND SCARCITY BY PERIURBAN FARMERS", A paper prepared at the 11th (EAAE), Kopenhagen, Denmark, $2005, P_{3}$.

\section{References}

[1] Ahmed, Muhammad Shehab, and Muamal Alaeddin, "The Space Requirements for City Planning", Higher Education Press, Baghdad, 1990, p. 121.

[2] Al-Duuji, Mumtaz, "The Influence of Morphological Changes in the Urban Fabric on its Structural Properties", A Study on Mosul Old City, Mosul University, 2011, P.5 .

[3] Al-Taif, Prof. Bashir Ibrahim, and Prof. Mohsen Abd Ali, and Prof. Riad Kazem AlJumaili, "City Services", A Study in Geographical Development, Lebanon, 2009, p. 109.

[4] Al-Hitti, Sabri Fares, "Geography of Cities", Dar Safa for Publishing and Distribution, Amman, 1st edition , 2010, p. 149.

[5] Municipality of Baghdad, Department of Design, Department of Geographic Information, 2017.

[6] Shaqair, Hiba Mohamed Hamouda, "Distribution and Planning of Educational Services in Salfit Governorate", Master Thesis, An-Najah National University, Palestine, 2009, P.39 .

[7] Abdel Razzaq, Najil Kamal, and Nagham Faisal, "Efficiency of the Distribution of Educational Services in Adhamiya Region", Journal of Planning and Development, No. 16,2007, p.34 .

[8] Ministry of Planning, Central Division of Statistics, 1965, 1977, 1987 and 1997 statistics, 2012 and 2017 estimates.

[9] Ministry of Education, General Directorate of Baghdad Education, Rusafa / 3 , Department of Educational Planning, Statistics Division, 2017. 